\title{
Trapping, chemistry, and export of trace gases in the South Asian summer monsoon observed during CARIBIC flights in 2008
}

Armin Rauthe-Schöch et al.

Correspondence to: Armin Rauthe-Schöch (armin.rauthe-schoech@mpic.de)

The copyright of individual parts of the supplement might differ from the CC-BY 3.0 licence. 


\section{Supplement to \\ "Trapping, chemistry and export of trace gases in the South Asian summer mon- soon observed during CARIBIC flights in 2008"}

5 by A. Rauthe-Schöch et al.

Correspondence to: Armin Rauthe-Schöch

(armin.rauthe-schoech@mpic.de)

\section{S1 Monsoon air during flight to Toronto in September 2007}

During two flights between Frankfurt, Germany and Toronto, Canada on 17 \& 18 September 2007 the CARIBIC aircraft encountered air transported from low altitude over South Asia. These air masses were intercepted between $59^{\circ} \mathrm{W}$ and $77^{\circ} \mathrm{W}$ at altitudes between $9.8 \mathrm{~km}$ and $11.3 \mathrm{~km}$. Measurements of greenhouse gases and volatile organic compounds contained in the three most air westerly samples during the two flights collected in these air masses revealed a characteristic "monsoon" signature as observed during subsequent flights to India in summer 2008 (see main text). Correlation plots of methane to ethane and ethane to propane we used to identify these samples marked by open symbols in Fig. S1. The "monsoon" signature includes elevated methane $\left(\mathrm{CH}_{4}\right)$ attributed to increased biogenic emissions during the monsoon season (Schuck et al., 2010; Baker et al., 2012), reduced carbon dioxide $\left(\mathrm{CO}_{2}\right)$ levels related to biogenic uptake (Schuck et al., 2010; Patra et al., 2011), elevated methylchloride $\left(\mathrm{CH}_{3} \mathrm{Cl}\right.$ (Umezawa et al., 2014) and elevated levels of combustion tracers (carbon monoxide (CO), ethyne, benzene) arising from wide-spread biofuel use (Baker et al., 2011). Ratios between these and other tracers (not shown) are similar to those observed in 2008, further supporting a source in the South Asian boundary layer.

Trajectory calculations with the FLEXPART Lagrangian particle dispersion model (Stohl et al., 2005, 2010) for the air samples with "monsoon" signature are shown in Fig. S2 (Flight to Toronto) and Fig. S3 (return flight to Frankfurt). The trajectories are started along the flight track during the sampling and by shifting the starting point arbitrarily in latitude and longitude by $\pm 0.4^{\circ}$ and in pressure by $\pm 3 \%$ to indicate the trajectory uncertainty. All six samples show rapid transport in the jetstream over East Asia and the Pacific Ocean. The trajectories also show that the air masses have been in the free troposphere or even close to the surface over India, Mainland Southeast Asia or China where they have picked up the typical "monsoon" signature.

Although CARIBIC collected a total of 493 air samples over North America $\left(140^{\circ} \mathrm{W}-55^{\circ} \mathrm{W}, 25^{\circ} \mathrm{N}-85^{\circ} \mathrm{N}\right)$ over five years between 2007 and 2013, no other case of such long-range transport of air with a clear monsoon signature has been observed. 


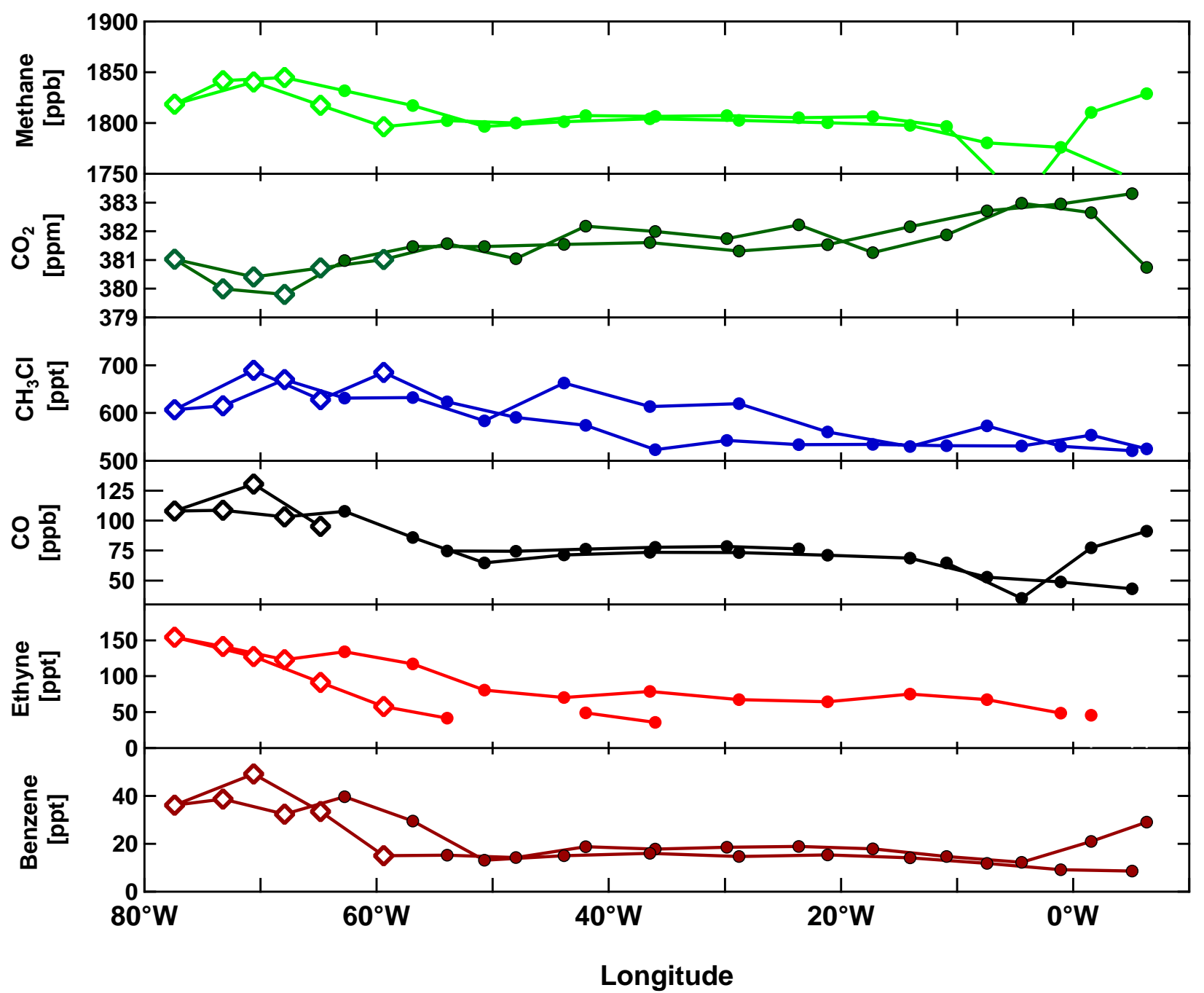

Figure S1. Methane $\left(\mathrm{CH}_{4}\right), \mathrm{CO}_{2}, \mathrm{CH}_{3} \mathrm{Cl}$, ethyne and benzene data from air samples collected during the CARIBIC flights between Frankfurt, Germany and Toronto, Canada on $17 \& 18$ September 2007. The air samples with a "monsoon signature" are shown by open symbols. The values for $\mathrm{CO}$ were integrated over the air sampling intervals from the continuous $\mathrm{CO}$ measurements. The flight to Toronto collected air samples up to $70.6^{\circ} \mathrm{W}$; the return flight started air sample collection at $77.4^{\circ} \mathrm{W}$. The missing $\mathrm{CO}$ data point at $59^{\circ} \mathrm{W}$ is due to calibration of the CO instrument during the air sample collection. The sample at $4.4^{\circ} \mathrm{W}$ (out of scale in both $\mathrm{CO}$ and methane) is stratospheric air. 

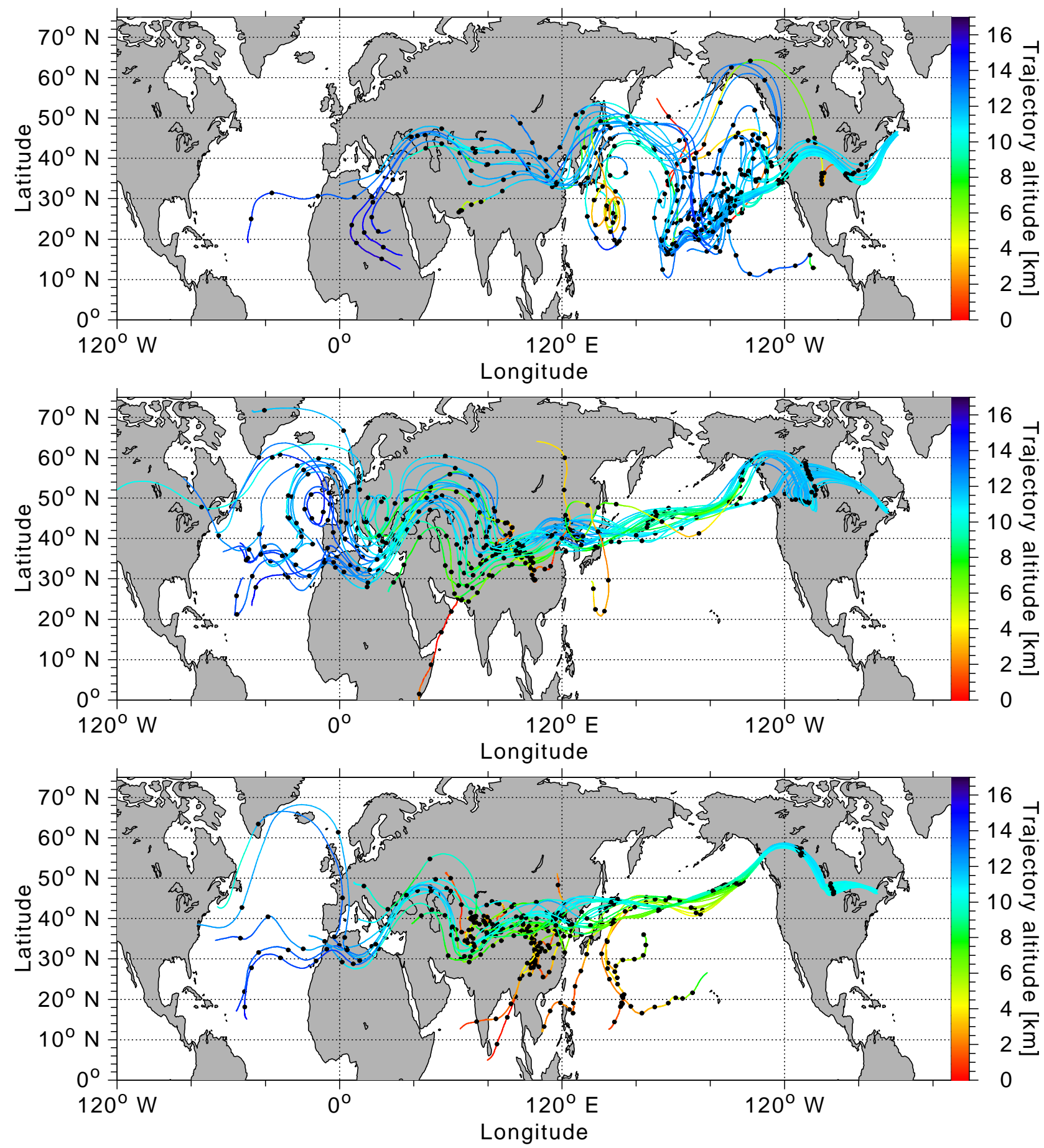

Figure S2. 16 day backward trajectories calculated with FLEXPART for the three most westerly air samples during the flight from Frankfurt to Toronto on 17 September 2007. The black dots mark $24 \mathrm{~h}$ time intervals along the backward trajectories. Air sample longitudes from top to bottom panel: $59.4^{\circ} \mathrm{W}, 64.8^{\circ} \mathrm{W}, 70.6^{\circ} \mathrm{W}$. 

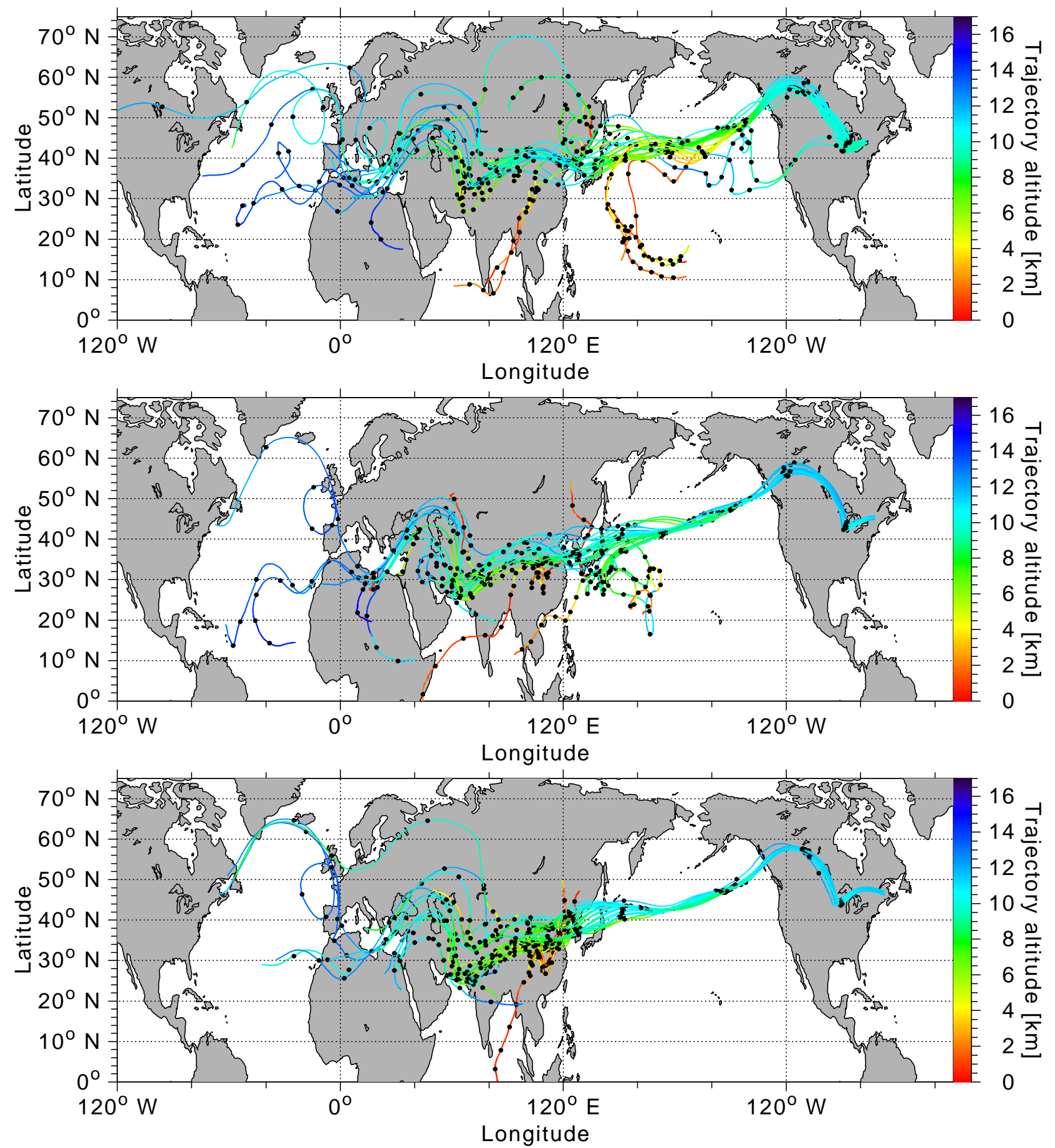

Figure S3. Same as Fig. S2 but for the flight from Toronto back to Frankfurt on 17 September 2007. Air sample longitudes from top to bottom panel: $77.4^{\circ} \mathrm{W}, 73.2^{\circ} \mathrm{W}, 67.9^{\circ} \mathrm{W}$. 


\section{S2 CARIBIC flight tracks}

This section shows more detailed plots of the flight tracks for the CARIBIC flights during the monsoon period June-September 2008. Figure S4 shows the flight altitude south of the northern cut-off latitude for the monsoon region (see Table 1). The aircraft usually climbs towards the end of the flight when the aircraft weight decreases due to the burnt fuel and cruising at higher altitude becomes more economical. Other reasons like avoiding other air traffic may require a change to the lower flight level (see e.g. one of the June flights to Chennai). The aircraft landed in Chennai always shortly before midnight local time. The take-off took place in the early morning between $2 \mathrm{AM}$ and 3:30 AM local time.

Figure S5 shows the flight tracks colour-coded by month. The CARIBIC passenger aircraft follows fixed flight corridors. Therefore the routes are very similar in each month. This also means that we have probed the monsoon upper troposphere anticyclone (UTAC) always at very similar geographical positions and observed changes of the monsoon circulation, like e.g. the latitude of the zonal wind reversal, are due to a shift in the UTAC itself.

The approach to Chennai is shown in more detail in Fig. S6. Since the general wind direction close to the surface is from the west, the aircraft lands in Chennai with headwind from the east and takes off to the west. September is an exception where the aircraft took off towards the east due to local surface winds from the east at these days at Chennai Airport.

\section{S3 Tropospheric winds}

Figure S7 shows daily mean winds from the ECMWF at the $745 \mathrm{hPa}$ model level for the days with CARIBIC flights to or from Chennai in 2008. July was special in that there were very weak winds over Southern India in a region around Chennai on the days of the CARIBIC flights. This may be an explanation for the different vertical profiles of e.g. aerosol particles, ozone or water vapour (see Sect. 3.1.3).

Figure S8 shows the daily mean winds from ECMWF at the $510 \mathrm{hPa}$ model level ( $\sim 5 \mathrm{~km}$ altitude). This is close to the wind reversal altitude (see Fig. 8 in main text) for June-August and still in the lower troposphere regime with eastward winds in September. 


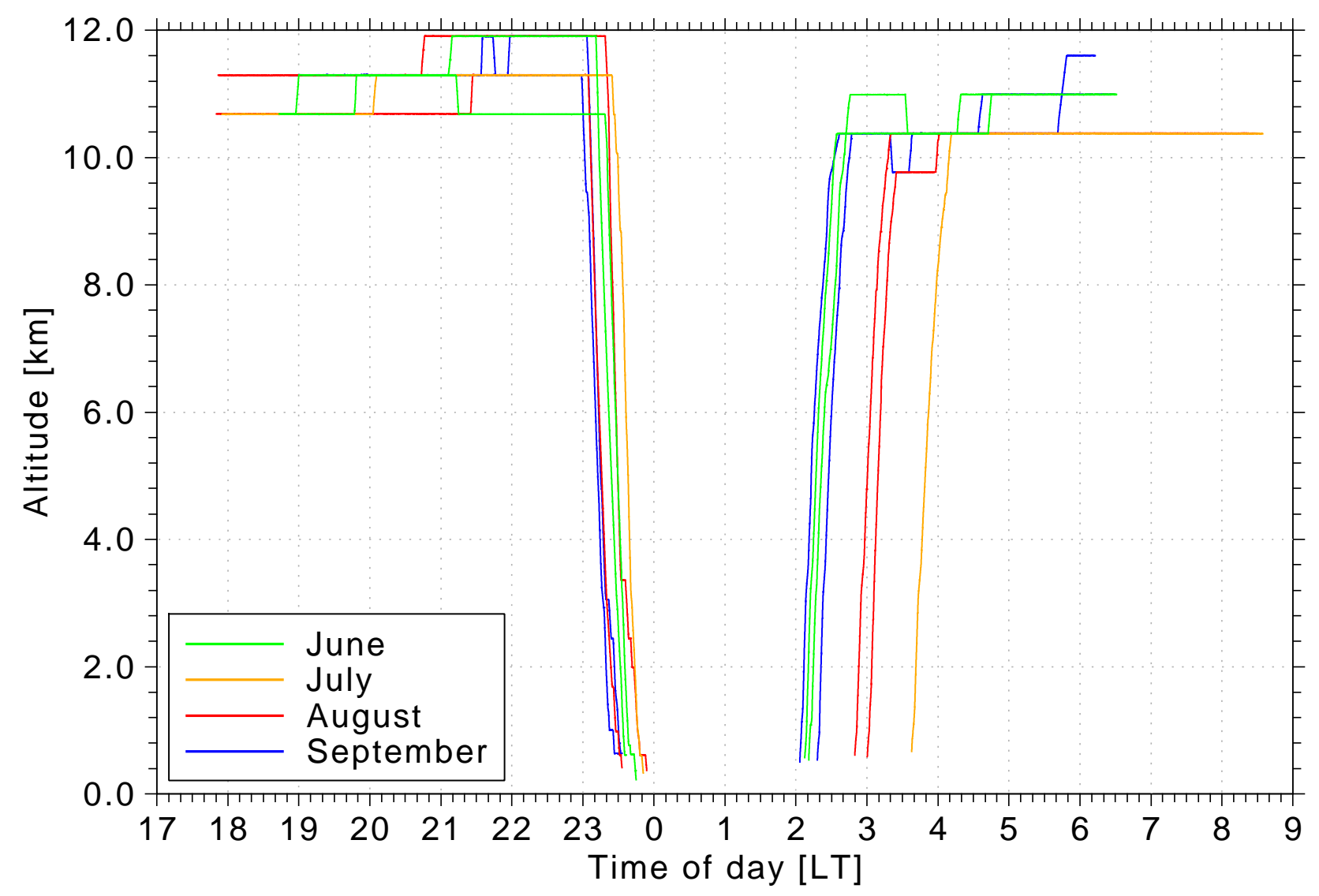

Figure S4. Altitude of the CARIBIC flights in the monsoon region south of the northern cut-off listed in Table 1. The aircraft landed in Chennai shortly before midnight local time (LT) and departed again between 2 AM and 3:30 AM LT. At cruise level the aircraft follows discrete constant pressure flight levels between $10300 \mathrm{~m}$ and $11900 \mathrm{~m}$. 


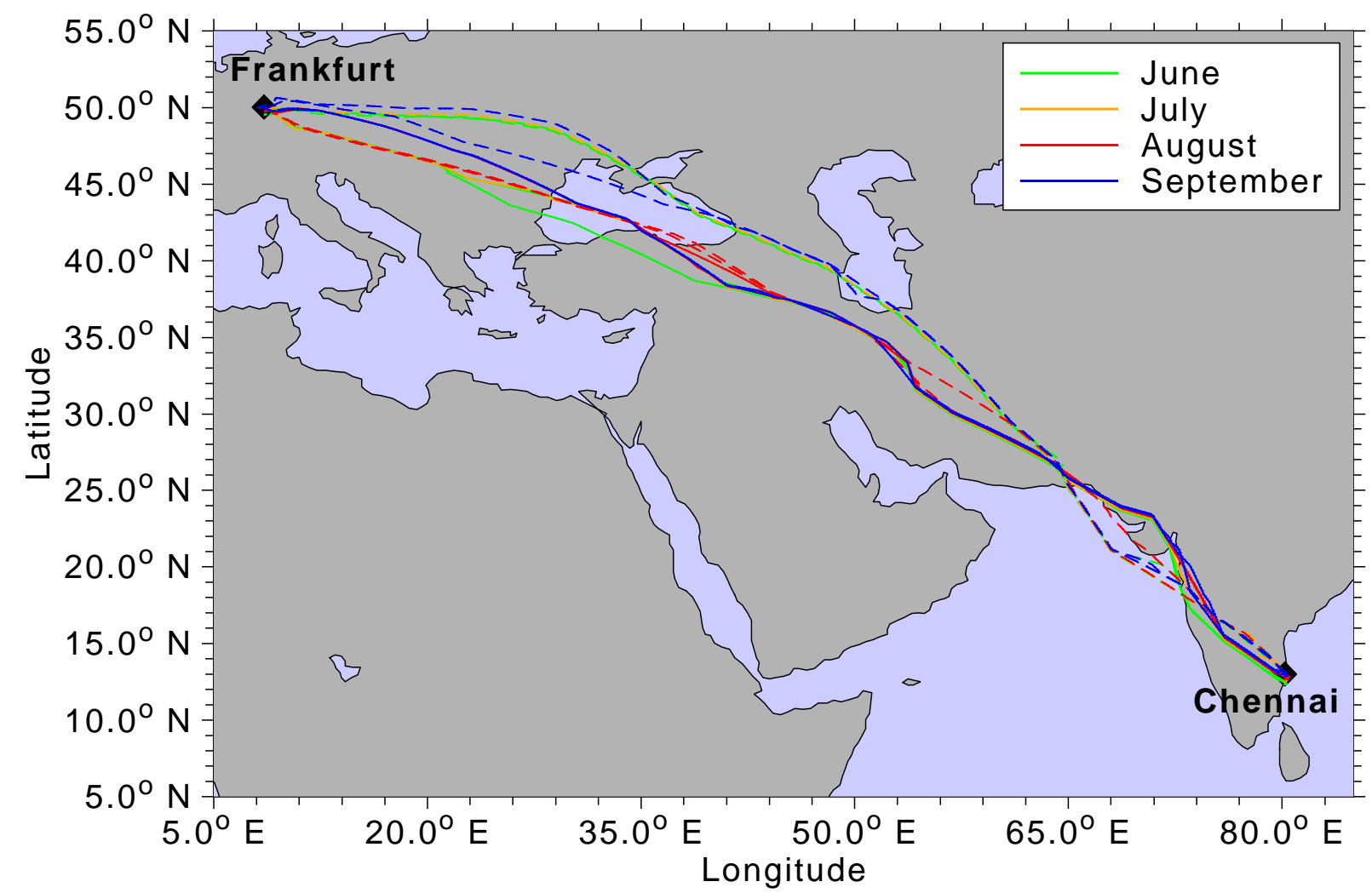

Figure S5. CARIBIC flight tracks between Frankfurt, Germany and Chennai, India in June-September 2008. Flights to Chennai are shown with solid lines, the return flights back to Frankfurt with dashed lines. 


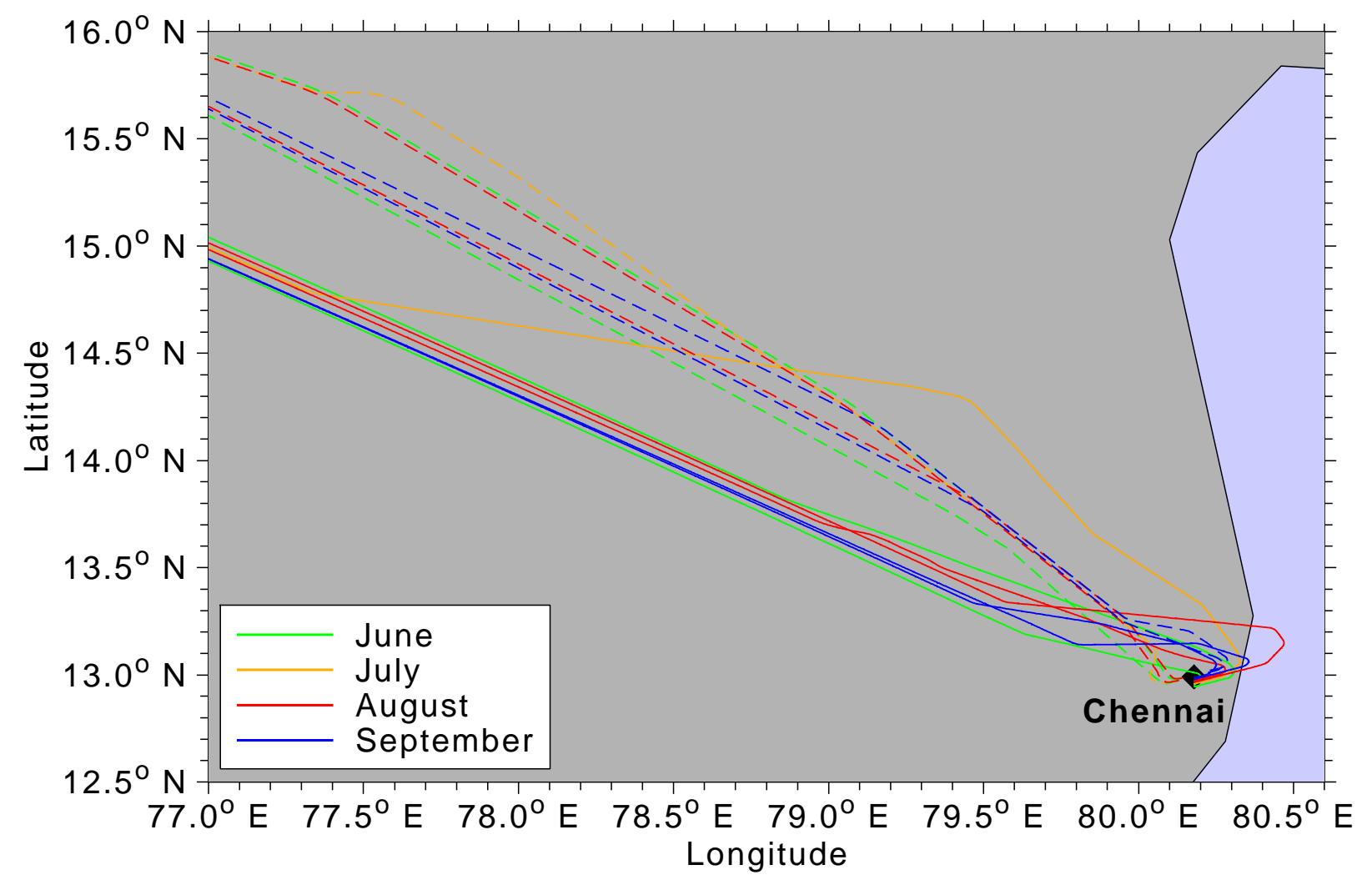

Figure S6. CARIBIC flight tracks during approach (solid lines) and take-off (dashed lines) to/from Chennai airport in June-September 2008. Approach is always from the east in headwind. Take-off is towards the west, except for September where the aircraft took off towards the east. 

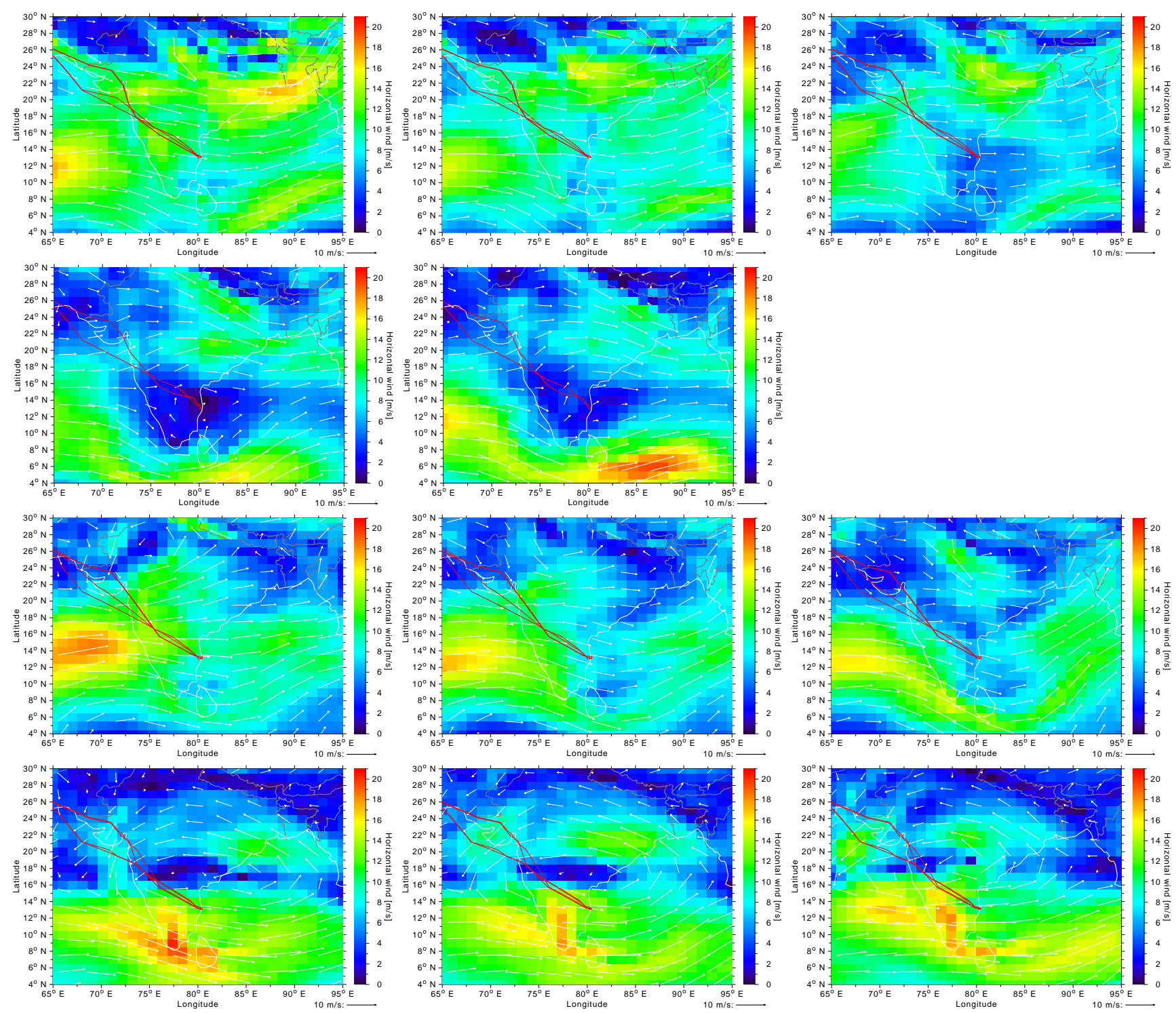

Figure S7. ECMWF mean daily winds at the 745 hPa model level for 18-20 June (first row), 15-16 July (second row), 13-15 August (third row) and 10-12 September 2008 (last row). The red lines show the flight tracks of the CARIBIC flights in the respective months. 

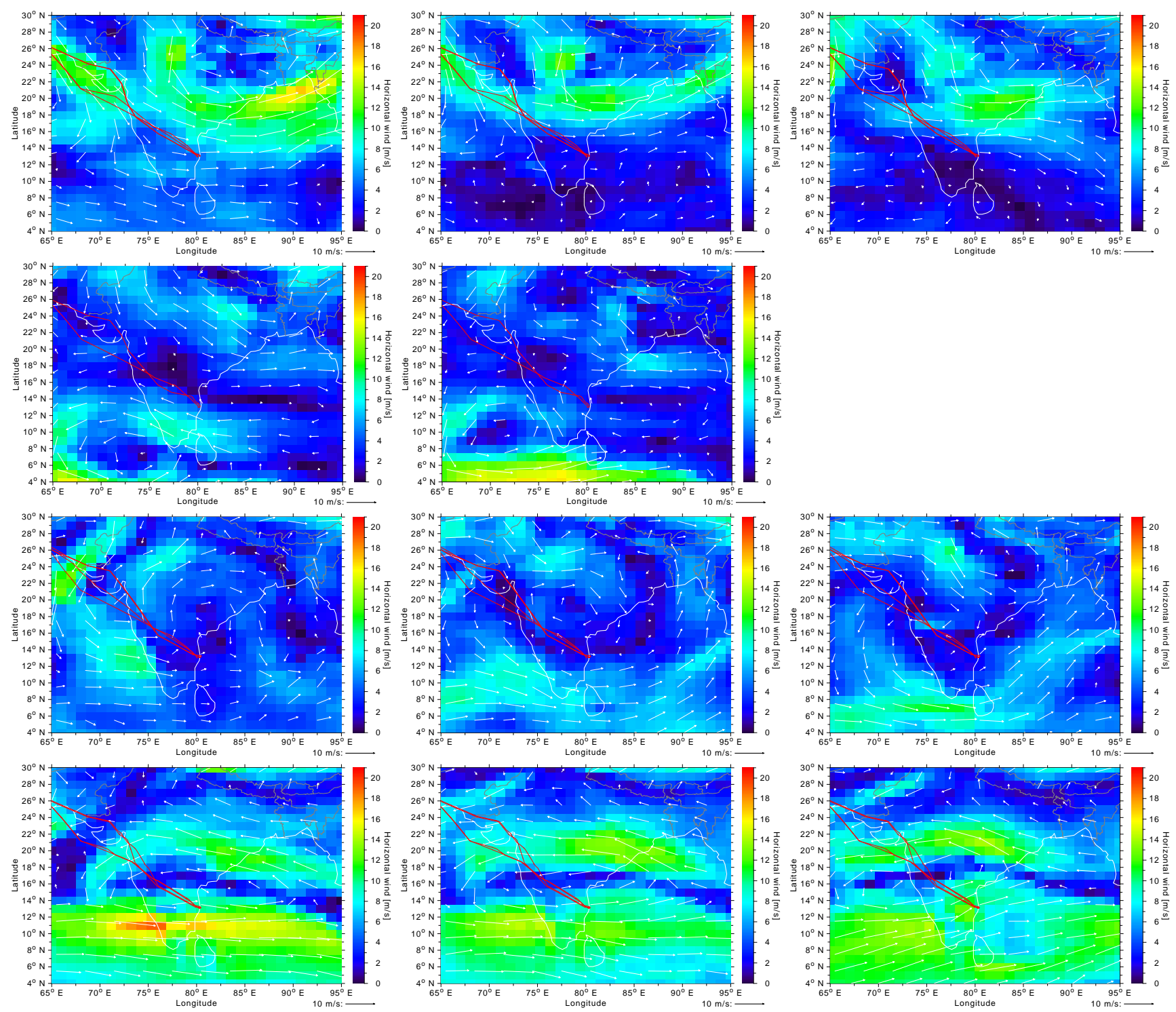

Figure S8. Same as Fig. S7 but for the $510 \mathrm{hPa}$ model level which is close to the wind reversal altitude in June to August and still shows the westward wind of the lower troposphere over Chennai in September 2008. 


\section{S4 CARIBIC observational data}

The observed trace gases relevant for this study are shown for one flight in the main text in Fig. 5. The following Figs. S9-S21 show the same set of trace gases for the other CARIBIC flights between Frankfurt and Chennai during the monsoon season June-September 2008.

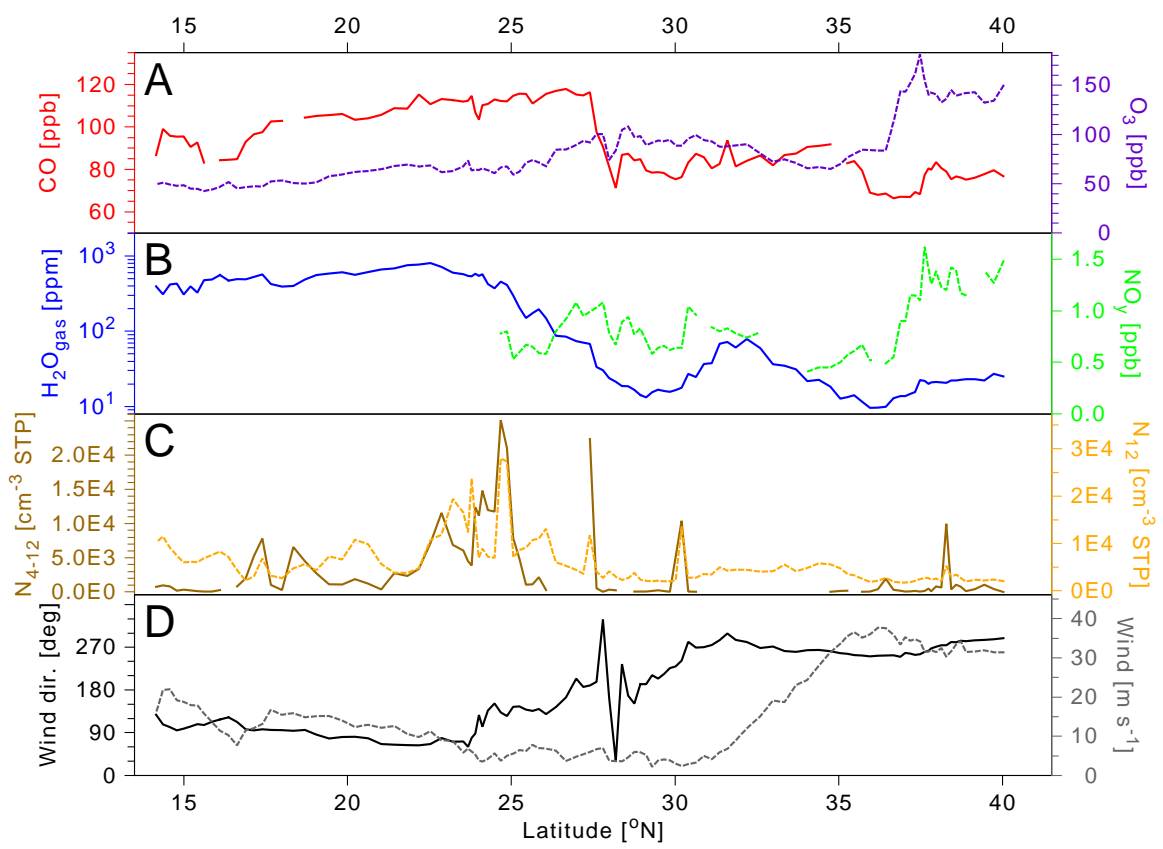

Figure S9. Latitudinal profiles of trace gases and meteorological parameters during the first flight in June from Frankfurt to Chennai on 18 June 2008. In addition to colour-coding of axes, scales for parameters represented by solid lines are on the left and scales for parameters represented by dashed lines are on the right (see Fig. 5 in main text). Aerosol particle number concentrations are given at STP (273.15 K, 1013.25 hPa). Note that all data is shown versus geographical latitude and that the water vapour shown in blue in panel B is on a logarithmic scale. 


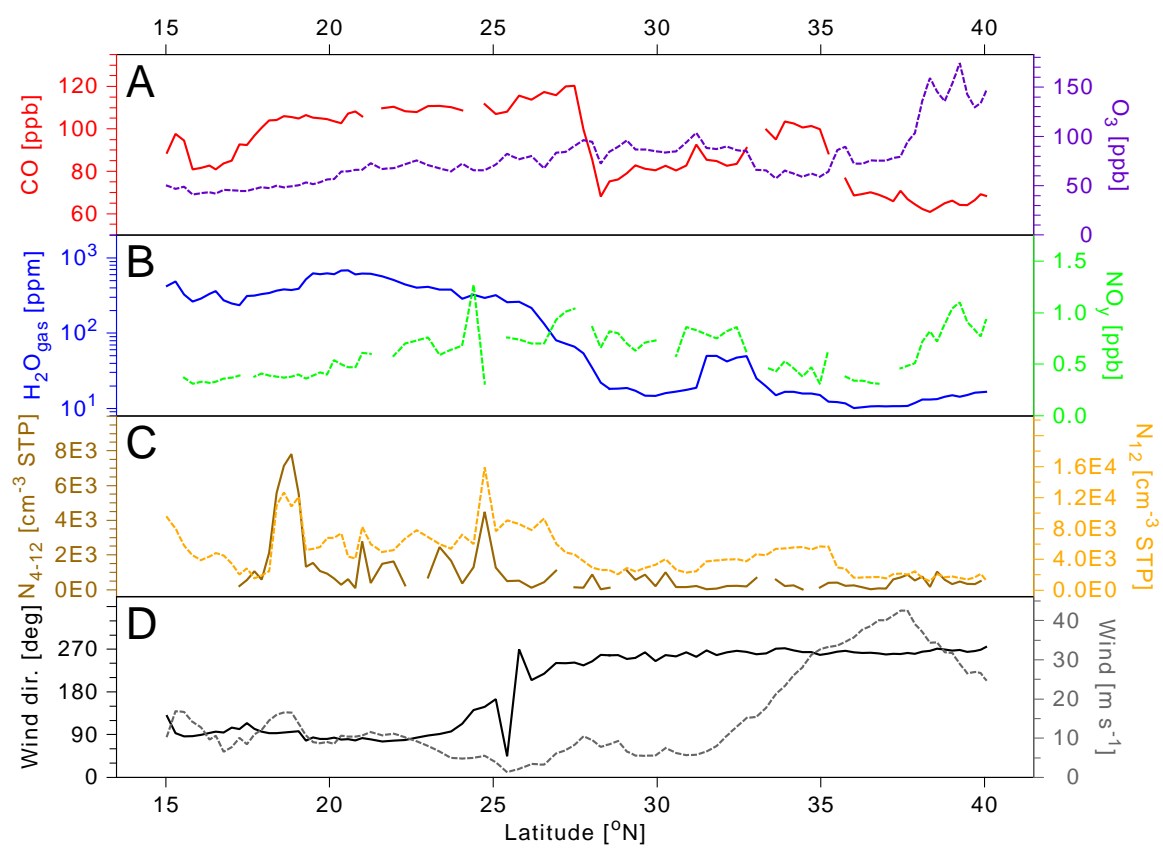

Figure S10. Same as Fig. S9 but for the first return flight in June from Chennai to Frankfurt on 18/19 June 2008.

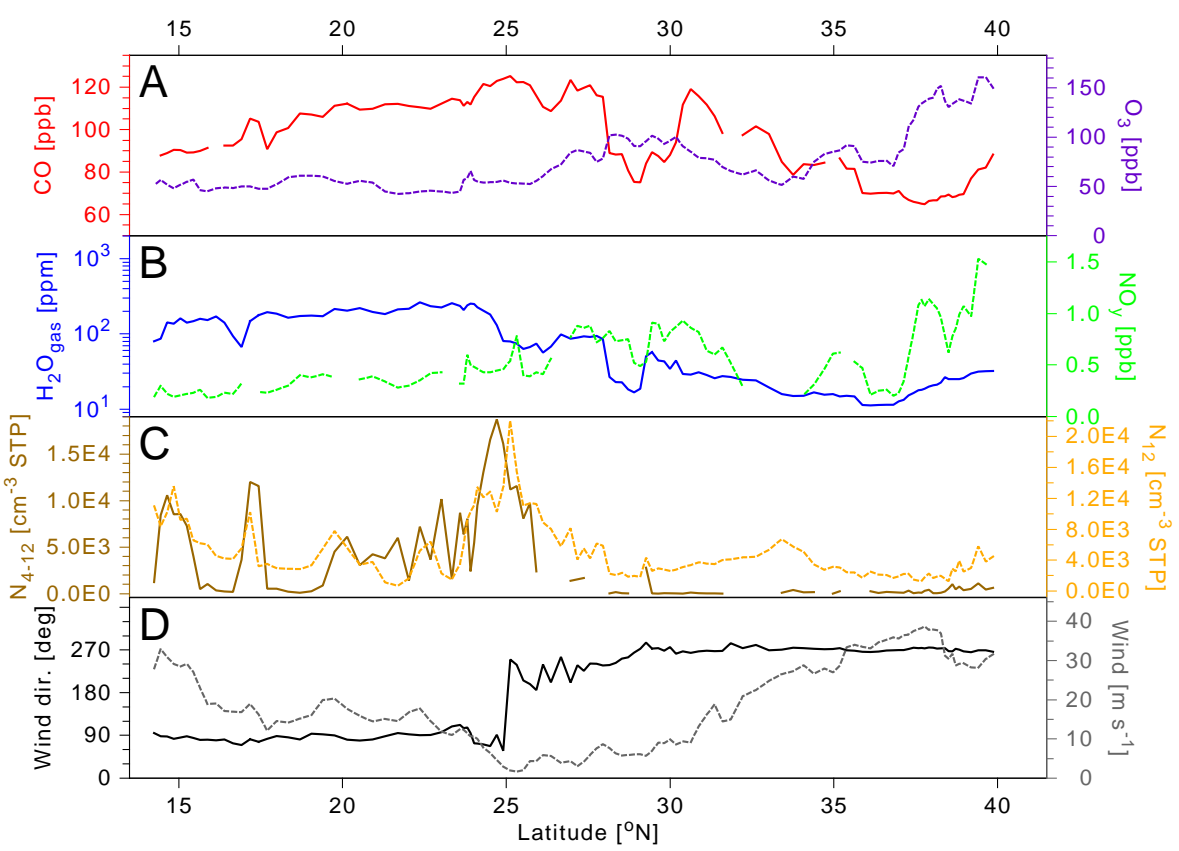

Figure S11. Same as Fig. S9 but for the second flight in June from Frankfurt to Chennai on 19 June 2008. 


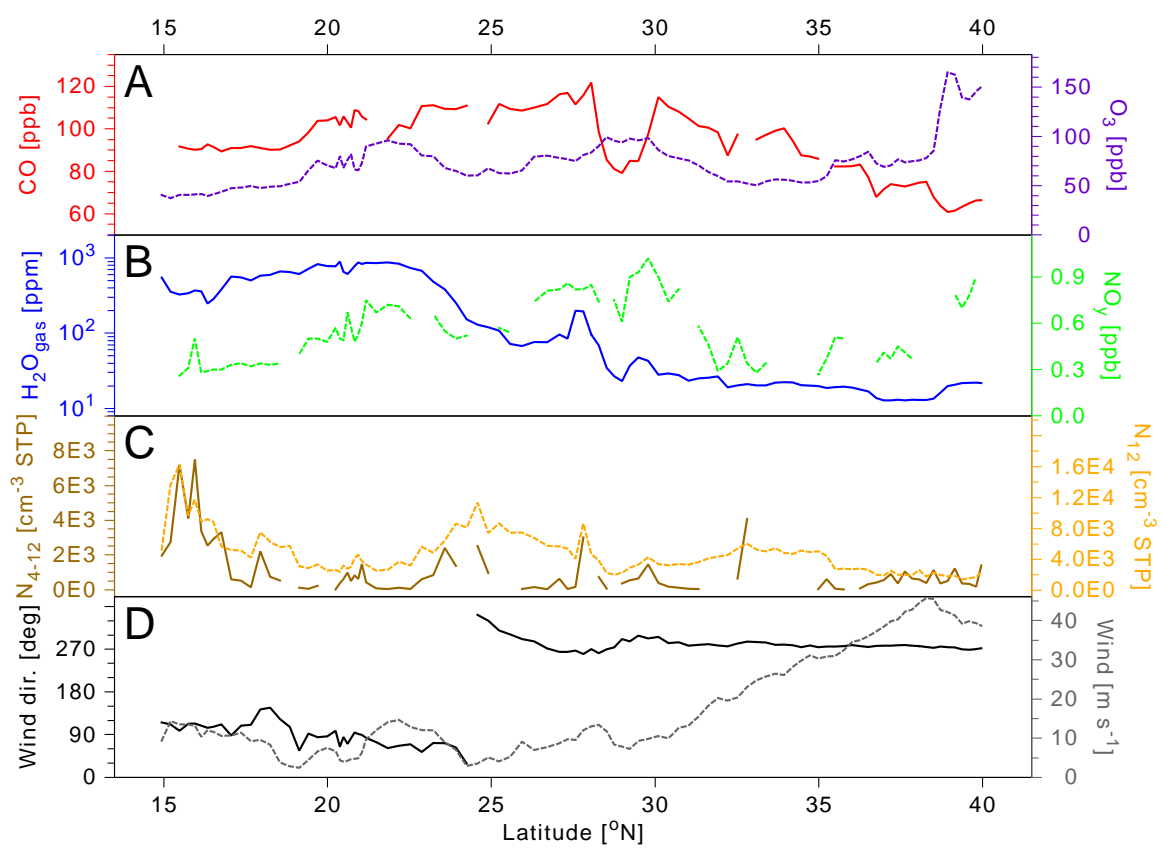

Figure S12. Same as Fig. S9 but for the second return flight in June from Chennai to Frankfurt on 19/20 June 2008.

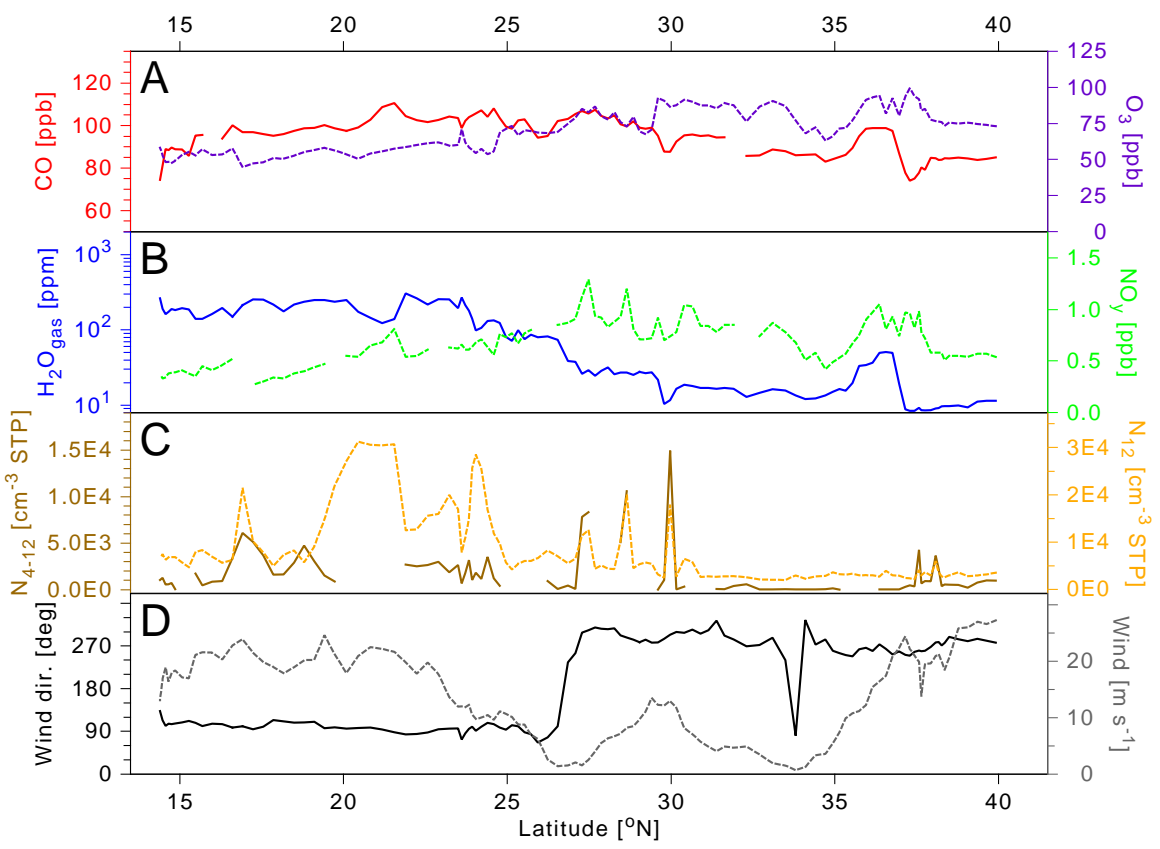

Figure S13. Same as Fig. S9 but for the flight in July from Frankfurt to Chennai on 15 July 2008. 


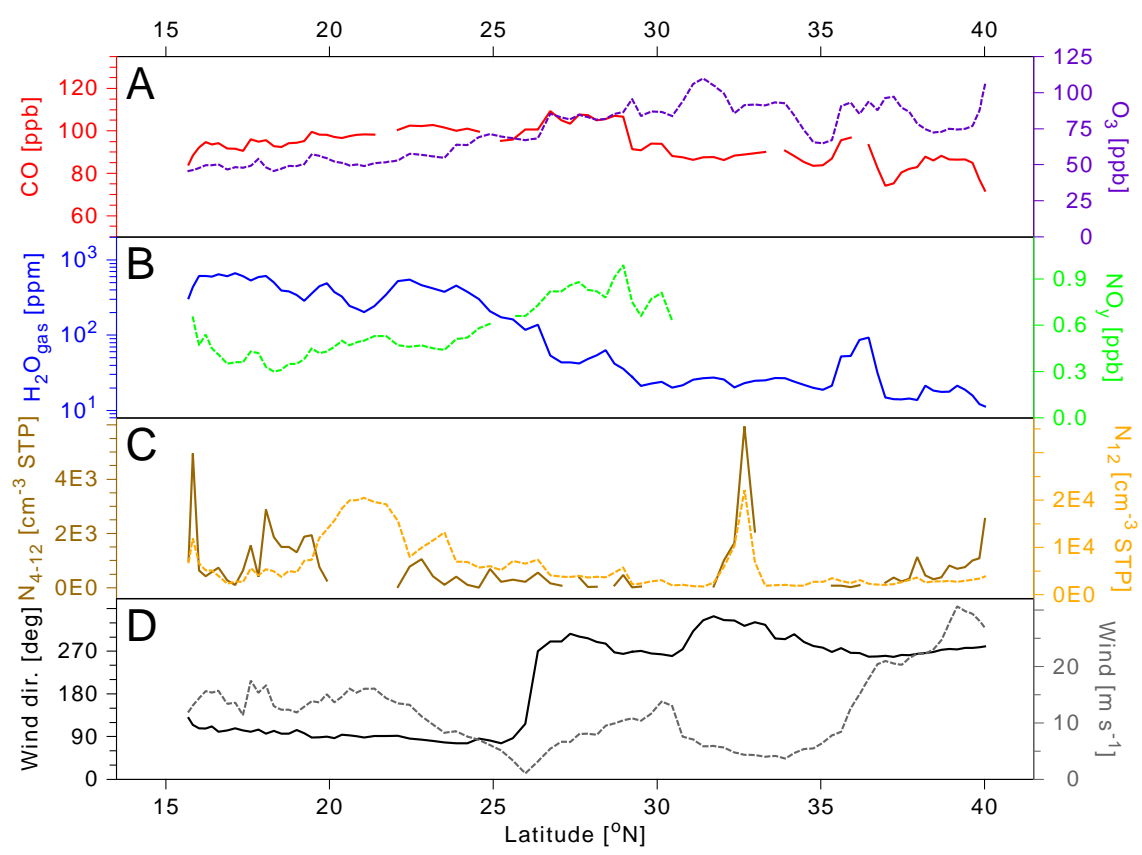

Figure S14. Same as Fig. S9 but for the return flight in July from Chennai to Frankfurt on 15/16 July 2008.

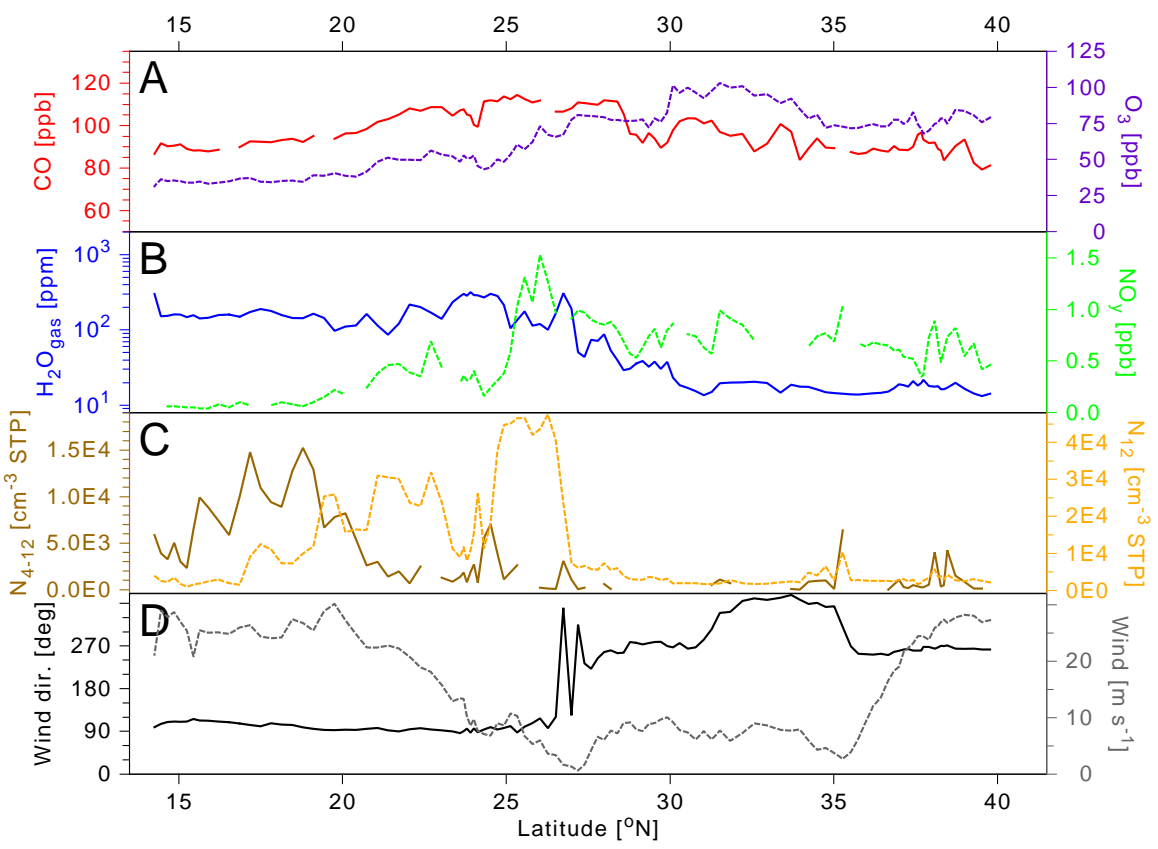

Figure S15. Same as Fig. S9 but for the first flight in August from Frankfurt to Chennai on 13 August 2008. 


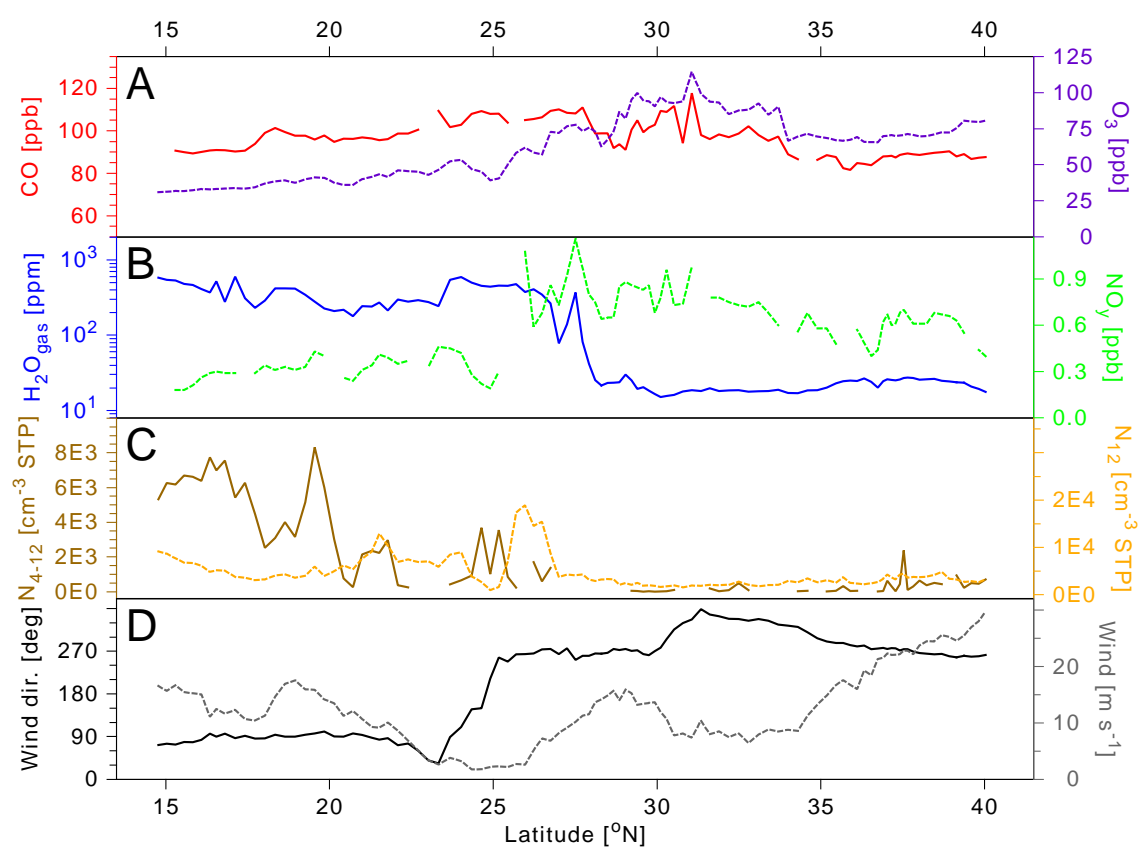

Figure S16. Same as Fig. S9 but for the first return flight in August from Chennai to Frankfurt on 13/14 August 2008.

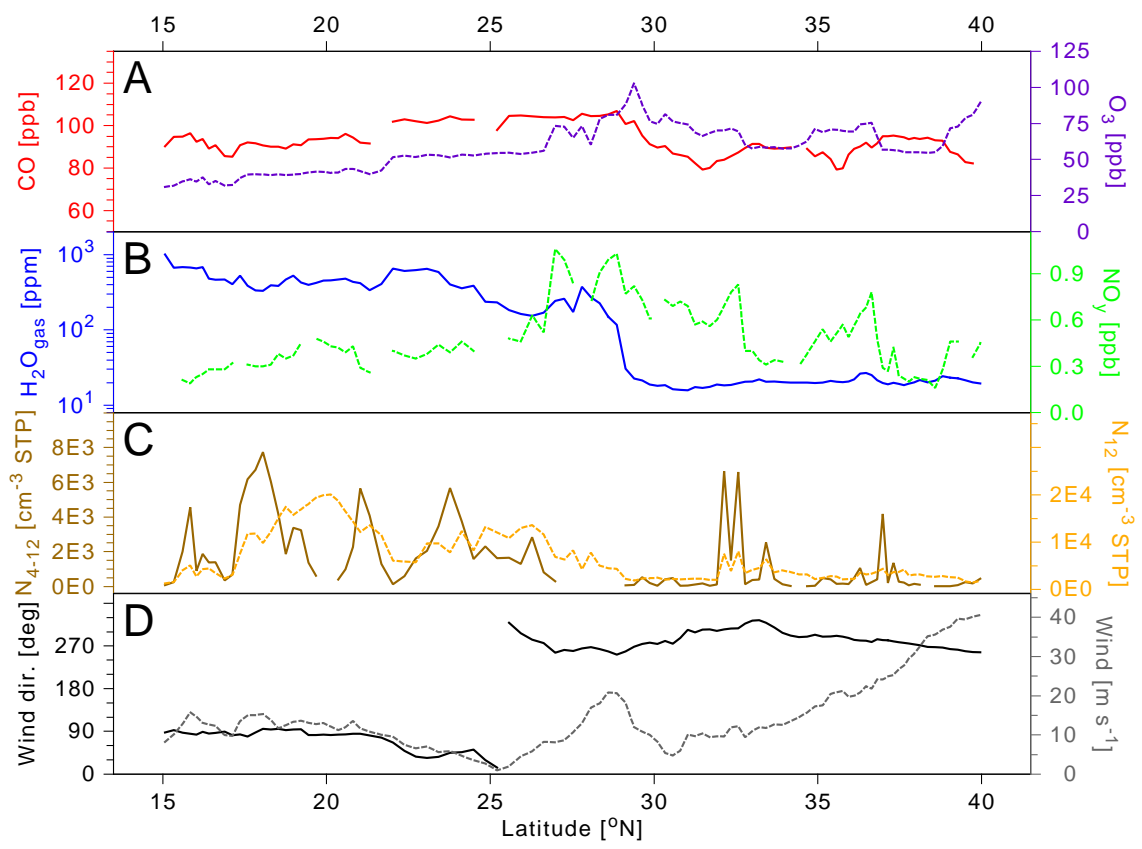

Figure S17. Same as Fig. S9 but for the second return flight in August from Chennai to Frankfurt on 14/15 August 2008. 


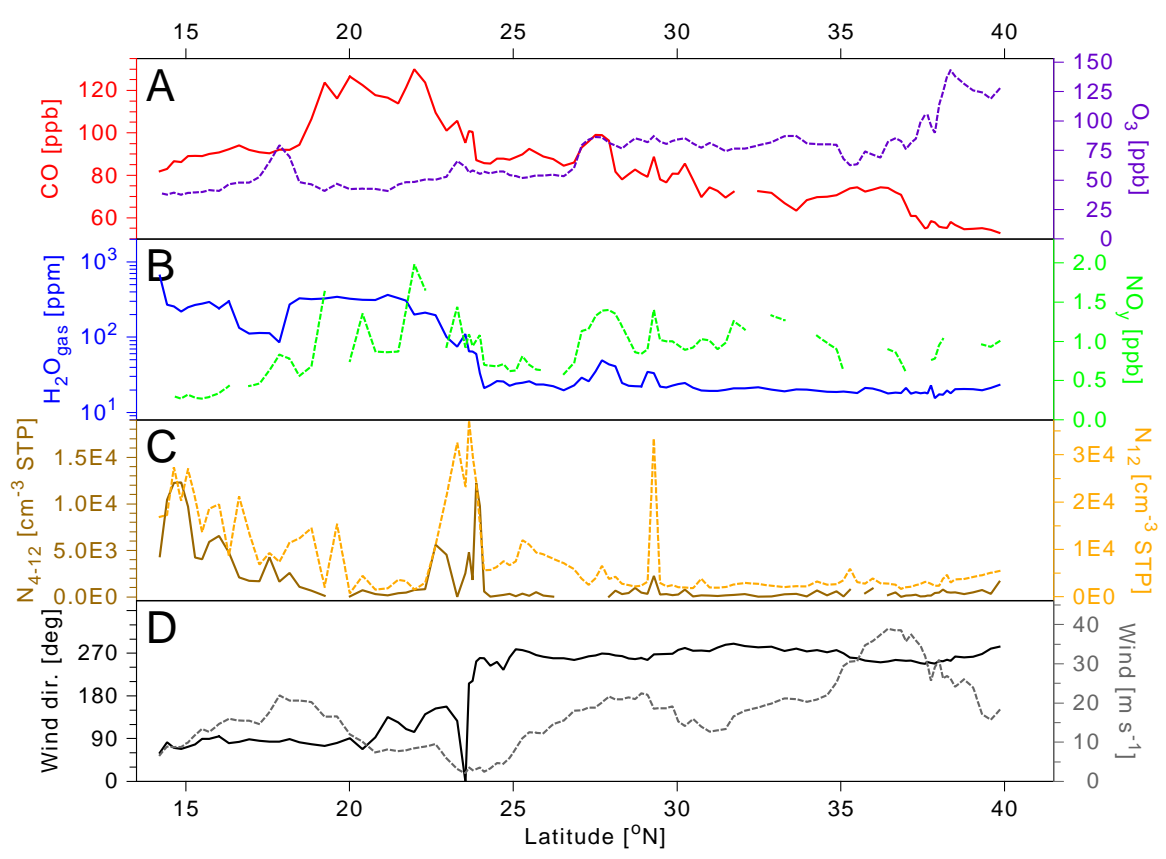

Figure S18. Same as Fig. S9 but for the first flight in September from Frankfurt to Chennai on 10 September 2008.

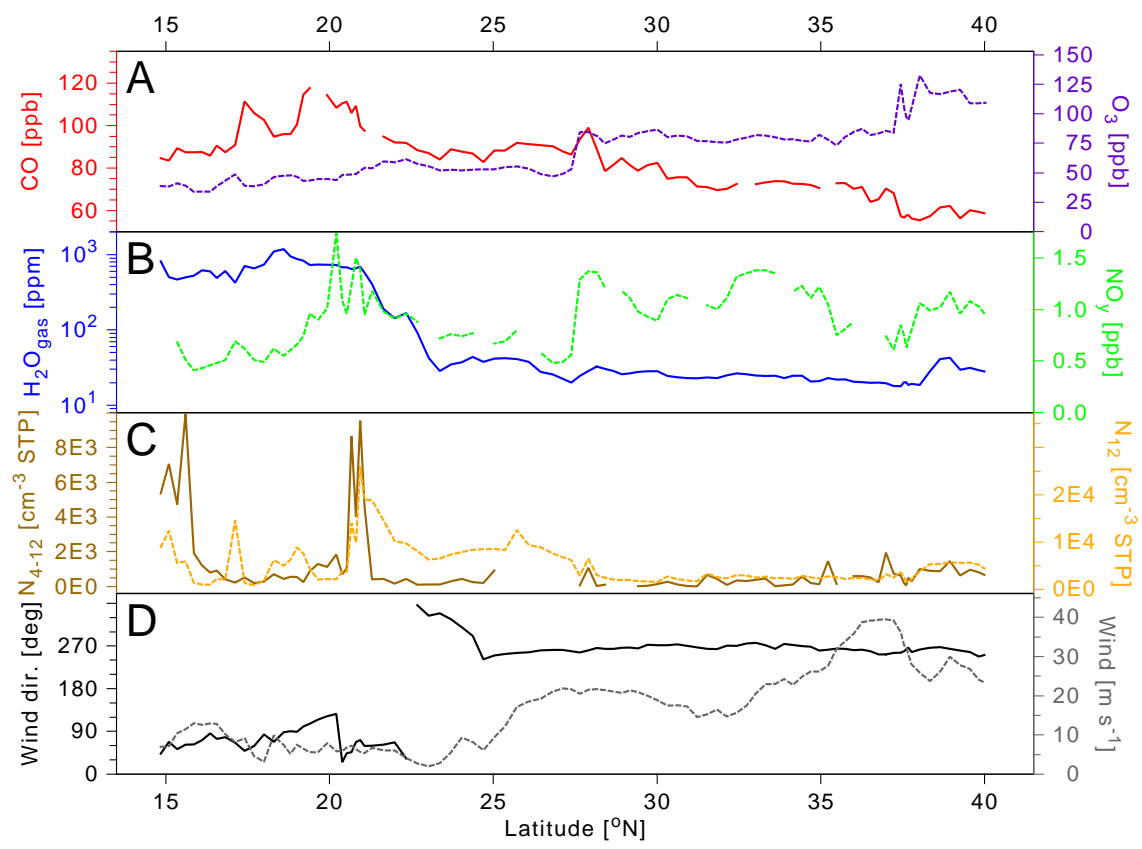

Figure S19. Same as Fig. S9 but for the first return flight in September from Chennai to Frankfurt on 10/11 September 2008. 


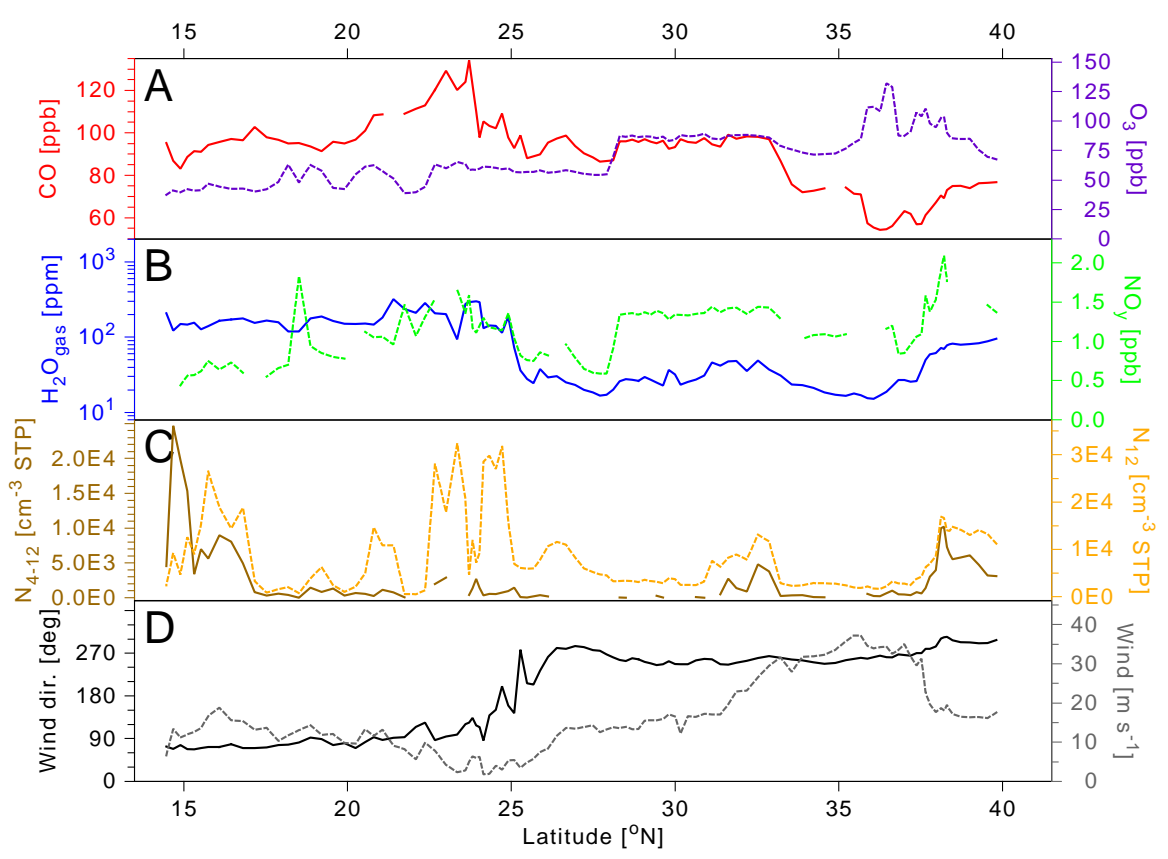

Figure S20. Same as Fig. S9 but for the second flight in September from Frankfurt to Chennai on 11 September 2008.

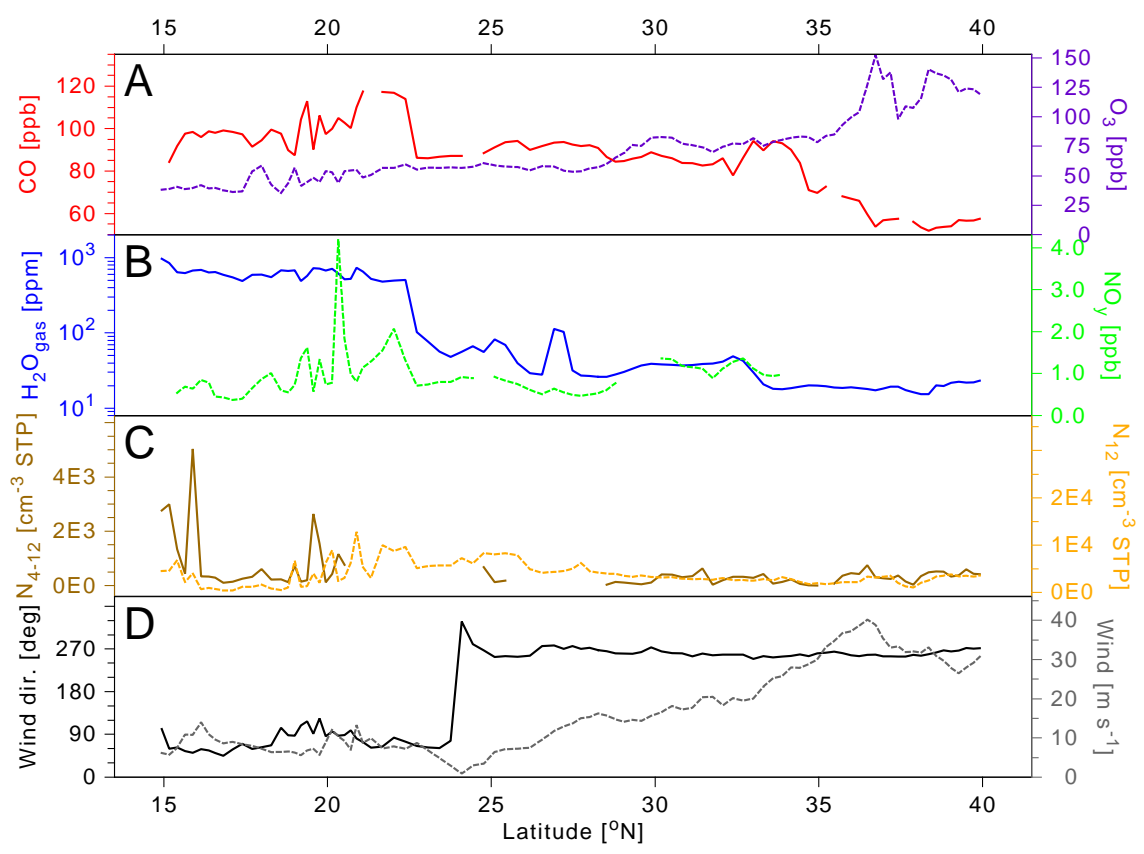

Figure S21. Same as Fig. S9 but for the second return flight in September from Chennai to Frankfurt on 11/12 September 2008. 


\section{S5 Monthly mean aerosol latitudinal distributions}

The high variability of the particle concentration data due to cloud contact has been discussed in Sect. 3.1.2. Particle concentrations for the single flights are presented in Fig. 5, Fig. 6 and Figs. S9-S21. Mean monthly latitudinal distributions of Aitken $\mathrm{N}_{12}$ and nucleation mode $\mathrm{N}_{4-12}$ particle number concentrations are presented below in Fig. S22 and Fig. S23, respectively.

5 The data have been binned into $3^{\circ}$ relative latitude bins. The error bars show the 1- $\sigma$ variability. The Aitken mode $\mathrm{N}_{12}$ data in Fig. S22 show how the vertical transport in deep convective clouds increases as the monsoon develops from June to August, mostly over the Bay of Bengal. The distributions of the Aitken mode particles reach north to relative latitudes $\Delta$ lat of $\sim 5^{\circ}$. As deep convective clouds are mostly located south of $23^{\circ} \mathrm{N}$, the lower concentrations at positive relative latitude are expected. The number concentrations of the nucleation mode $\mathrm{N}_{4-12}$ particles are generally larger south of the wind reversal $(\Delta$ lat $<0)$ except for July where it is more or less constant throughout the whole monsoon region (see Fig. S23). The nucleation mode $\mathrm{N}_{4-12}$ particles concentrations (Fig. S23) are much more sensitive to the exact location of the convective clouds and show therefore more variability.

Figure S24 shows the fraction of the nucleation mode particles $\mathrm{N}_{4-12}$ relative to the total particle concentration $\mathrm{N}_{4-12}+\mathrm{N}_{12}$ again in $3^{\circ}$ relative latitude bins. The largest fraction of nucleation mode particles and hence the youngest aerosol particle mixture from most recent convective events is found in the southern part of the monsoon UTAC at $\Delta$ lat of $-10^{\circ}$ to $-5^{\circ}$.
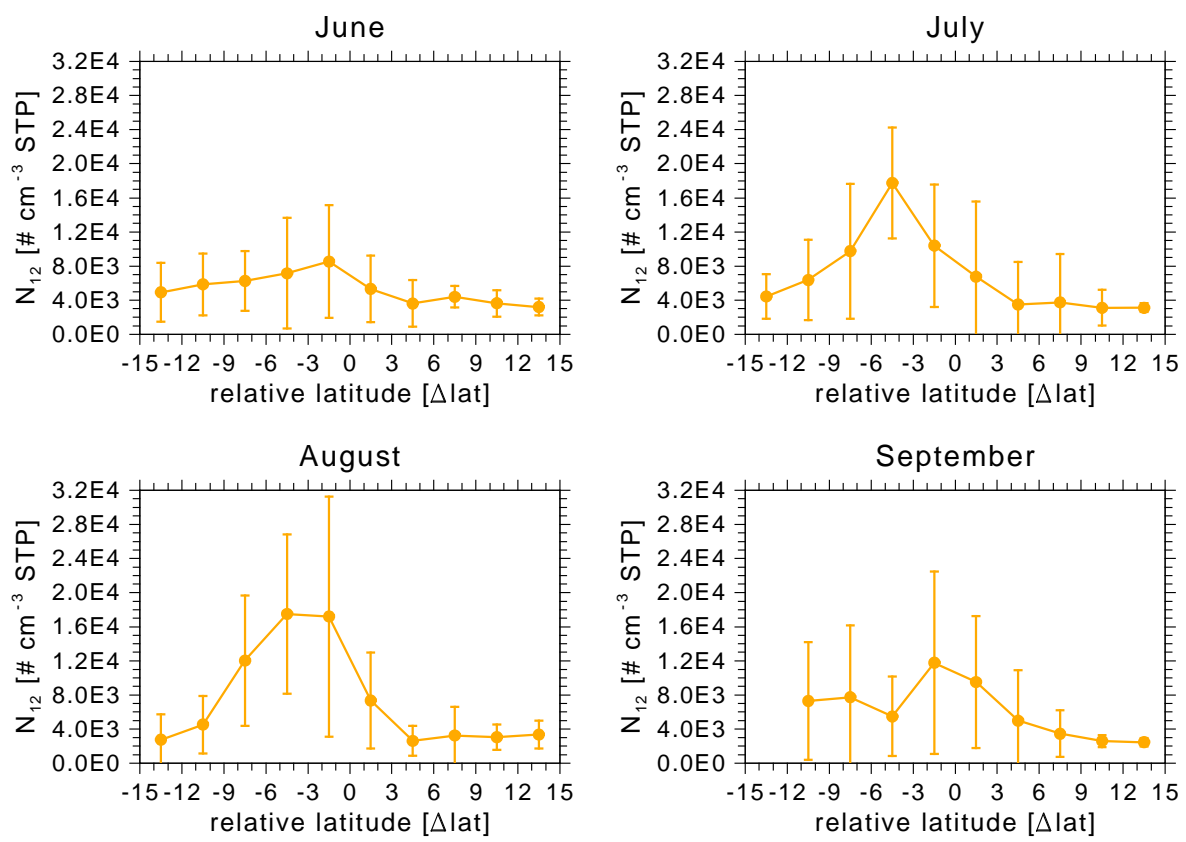

Figure S22. Monthly mean and 1- $\sigma$ variability of the Aitken mode $\mathrm{N}_{12}$ particle number concentrations at STP $(273.15 \mathrm{~K}, 1013.25 \mathrm{hPa})$. 

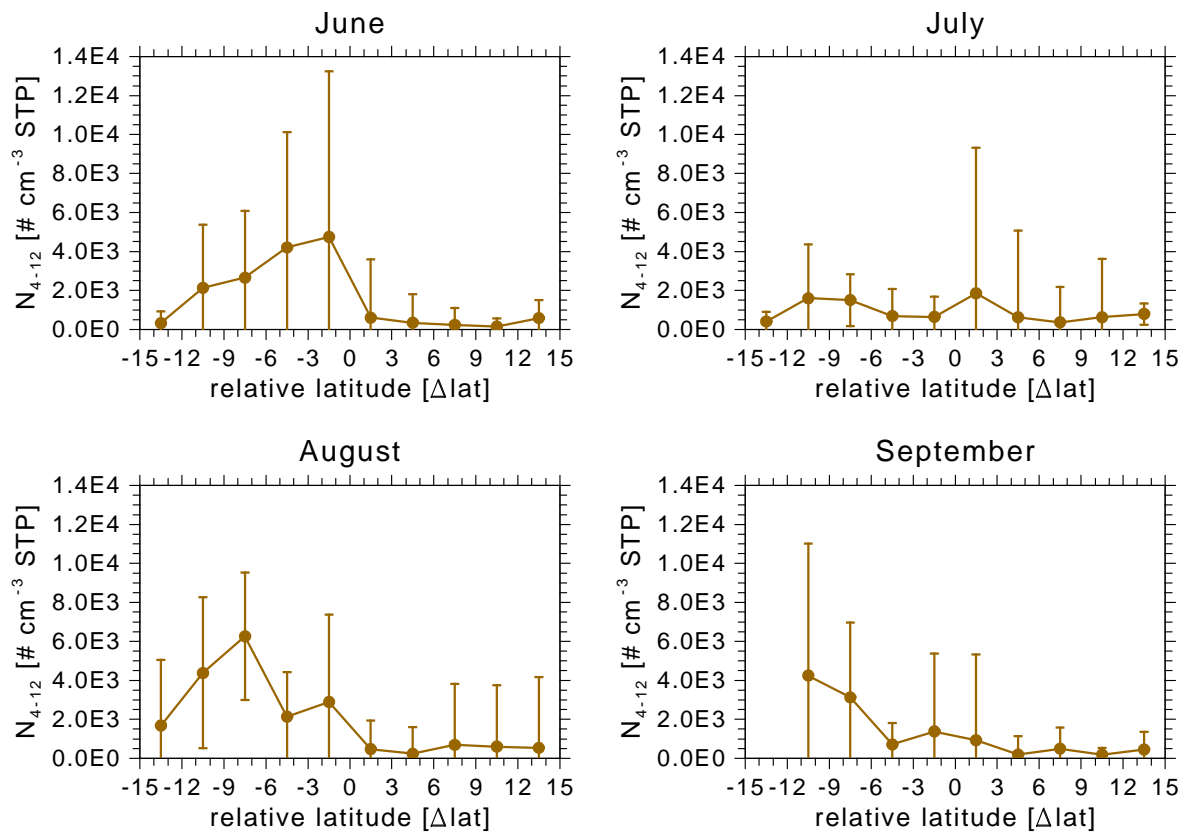

Figure S23. Monthly mean and 1- $\sigma$ variability of the nucleation mode $\mathrm{N}_{4-12}$ particle number concentrations at STP $(273.15 \mathrm{~K}$, $1013.25 \mathrm{hPa})$. 

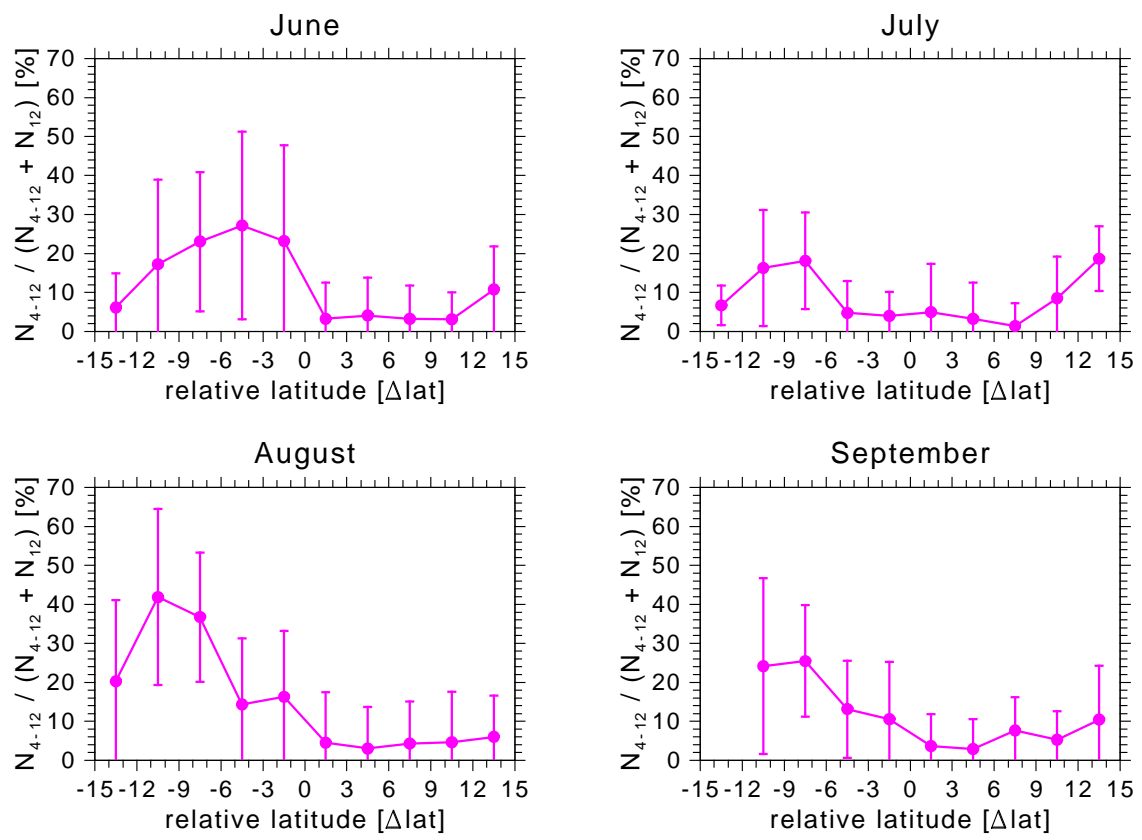

Figure S24. Monthly mean and 1- $\sigma$ variability of the fraction of nucleation mode particles $\mathrm{N}_{4-12} /\left(\mathrm{N}_{4-12}+\mathrm{N}_{12}\right)$ at STP $(273.15 \mathrm{~K}$, $1013.25 \mathrm{hPa}$ ). 


\section{S6 Ozone formation and destruction potential}

The relationship between $\mathrm{O}_{3}$ and $\mathrm{CO}$ in the monsoon UTAC as presented in Sect. 3.1.2 and Fig. 7 was further investigated through calculation of slopes of the correlations moving from south to north. Slopes were determined for data points falling into rolling $2^{\circ}$ latitude bins in an attempt to determine any patterns or trends in $\Delta \mathrm{O}_{3} / \Delta \mathrm{CO}$ and also to identify regions of particularly strong $\mathrm{O}_{3}$ formation or destruction (Fig. S25). At many points along the profiles, mostly when slopes are near 0 , no statistically significant relationship is observed. This is taken as an indication of an ambiguous relationship between $\mathrm{O}_{3}$ and $\mathrm{CO}$, which in turn can be indicative of a transition between $\mathrm{O}_{3}$ forming and $\mathrm{O}_{3}$ depleting regimes or of a region within the UTAC that is influenced by a number of air masses having different characteristics (e.g. presence of air parcels having very recent continental emissions along with air parcels having older emissions and/or marine boundary layer air).

10 This is supported by points having ambiguous relationships often falling between two regions having different characteristics (i.e. at the transition between positive and negative $\Delta \mathrm{O}_{3} / \Delta \mathrm{CO}$ ), or being encountered in regions of the UTAC where the meteorological and chemical regimes are themselves transitioning or ambiguous (i.e. $0^{\circ}-5^{\circ}$ north of the transition point).

From these analyses no clear pattern emerges that can be applied to all months, however, a number of features are common between months, and patterns in July and August, when the monsoon is fully developed, are fairly similar, although the magnitudes are quite different. Prominent during both months are periods of large, positive $\Delta \mathrm{O}_{3} / \Delta \mathrm{CO}$ immediately north of the transition point and between about $5^{\circ}$ and $10^{\circ} \Delta$ lat, indicating $\mathrm{O}_{3}$ forming regimes, separated by a period of ambiguous relationships where air parcels cannot be identified as either $\mathrm{O}_{3}$ forming or depleting. In general, positive values of $\Delta \mathrm{O}_{3} / \Delta \mathrm{CO}$ in July indicate the strongest $\mathrm{O}_{3}$ formation potential, while negative values or small positive values of $\Delta \mathrm{O}_{3} / \Delta \mathrm{CO}$ in June points to air parcels being mostly ozone destroying or only weakly ozone forming. The negative values seen in the very south are due to the influx of clean boundary layer air. Varying the size of the latitude bins leads to qualitatively similar results. However, very small latitude size bins do not contain enough data points for a robust linear regression and size bins much larger than $2^{\circ}$ average over different air masses. 


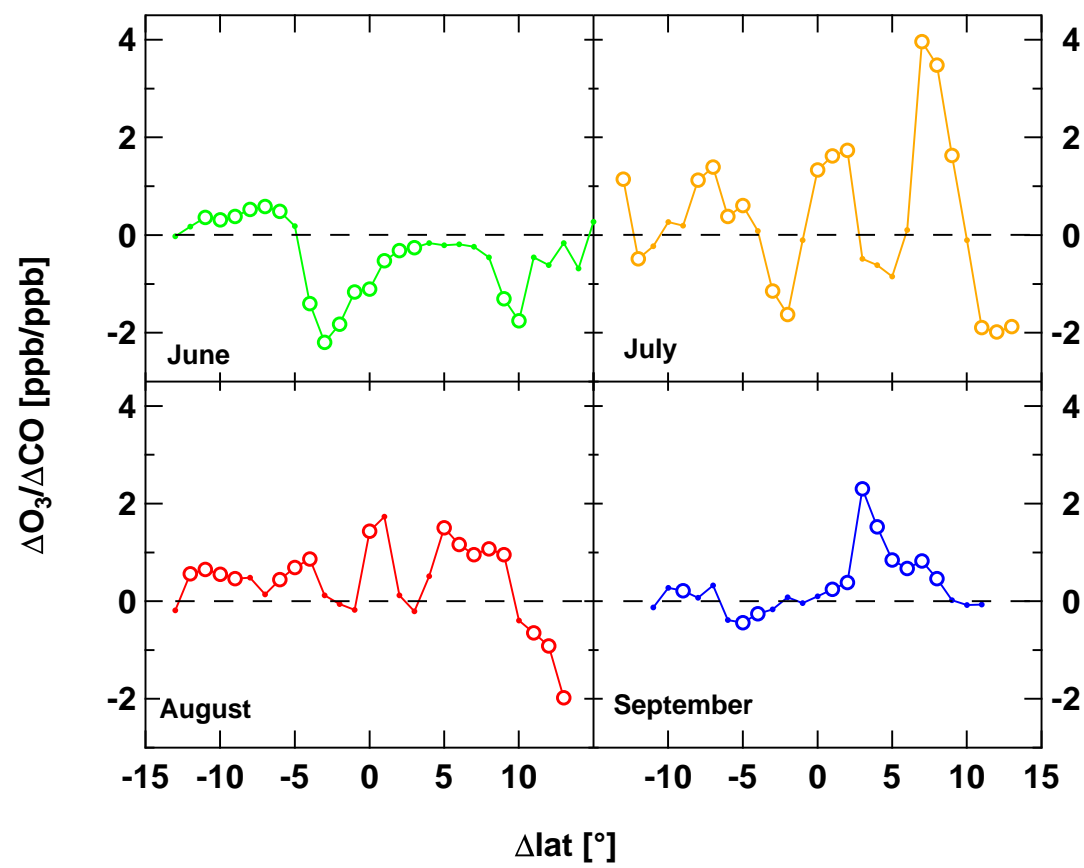

Figure S25. $\Delta \mathrm{O}_{3} / \Delta \mathrm{CO}$ calculated for rolling $2^{\circ} \Delta$ lat bins for each of the four monsoon months. Values of $\Delta \mathrm{O}_{3} / \Delta \mathrm{CO}$ were calculated from the slopes of the correlations for data points from all flights collected within each $\Delta$ lat bin. Large, open markers represent values where the slopes are significant (within $95 \%$ confidence interval CI); small, closed markers denote points with statistically insignificant slopes $(<95 \% \mathrm{CI})$. The dashed line represents a slope of zero. 


\section{S7 Source region plots for other months}

Section 3.2 has discussed the source regions of the air measured during the CARIBIC flights in the monsoon UTAC over India. Fig. 11 showed the source region distributions averaged over all flights in 2008. Figs. S26-S29 show the corresponding distributions for the flights splitted per month from June to September 2008.
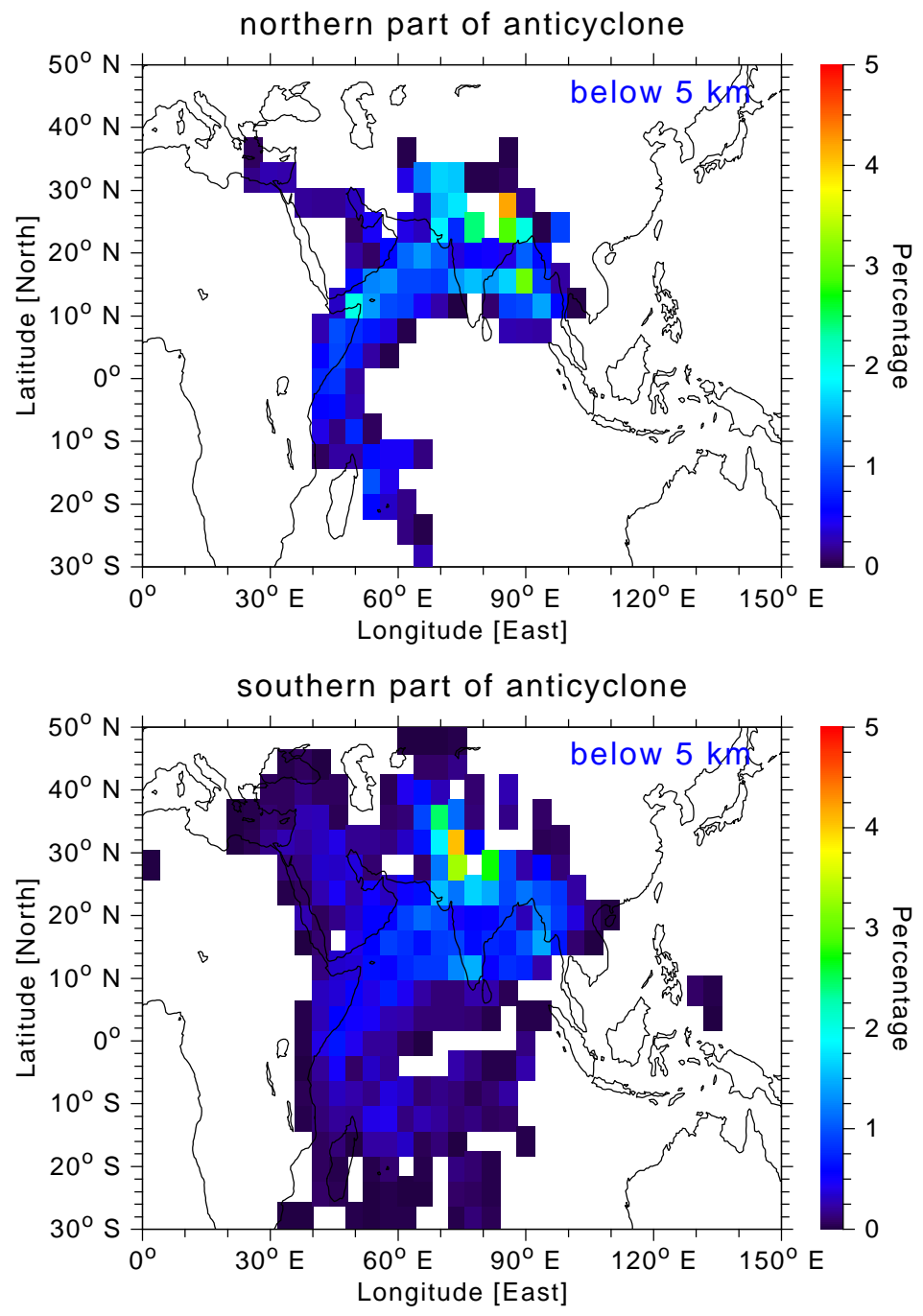

Figure S26. Distribution of source regions for the CARIBIC flights in June 2008. The colour code shows the percentage of trajectories that came from below $5 \mathrm{~km}$ altitude in the $4^{\circ} \times 4^{\circ}$ grid boxes. Upper panel: Source regions for trajectories starting north of the wind reversal. Lower panel: Source regions for trajectories starting south of the wind reversal. See also Fig. 11 in the main text. 

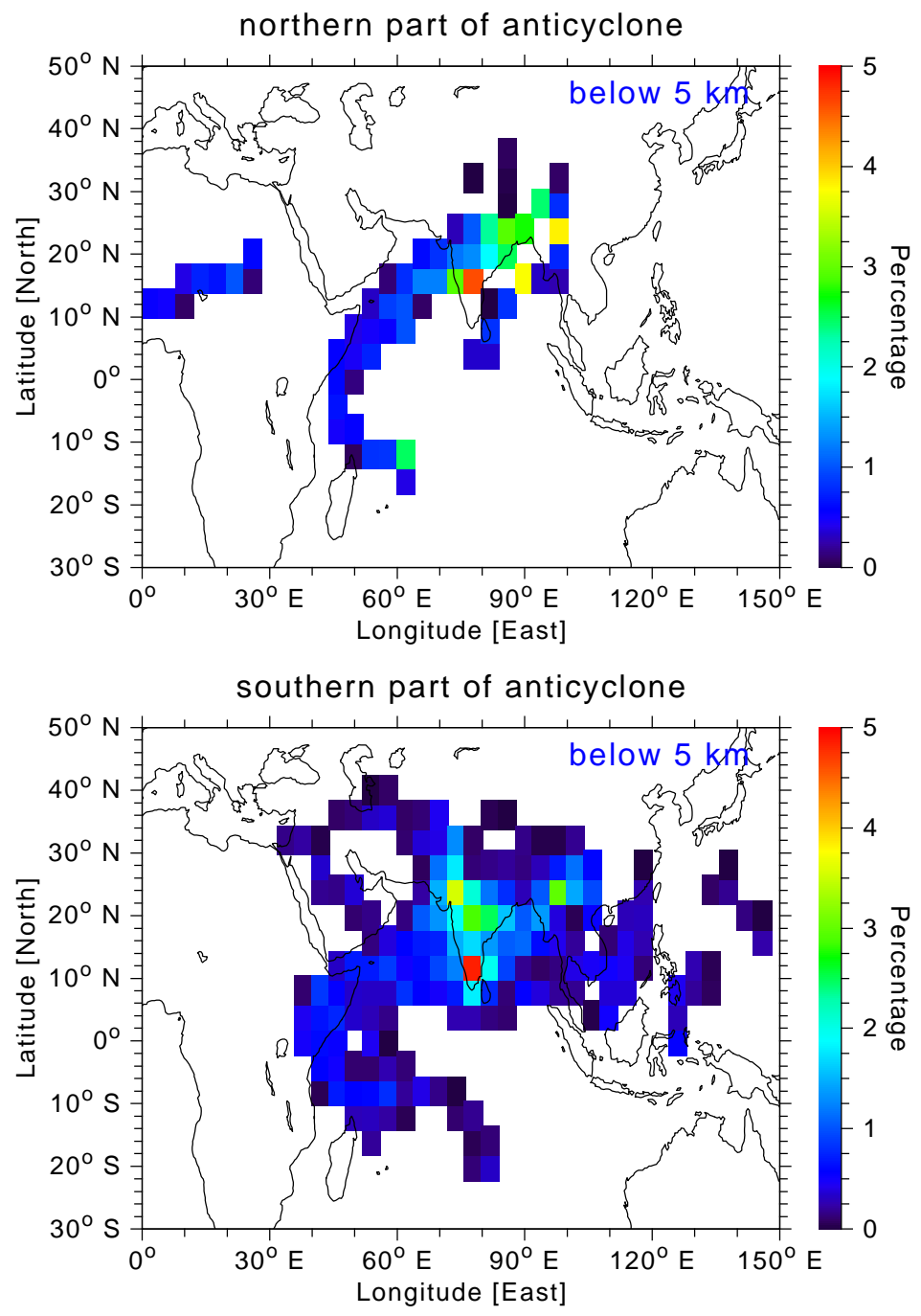

Figure S27. Same as Fig. S26 but for the CARIBIC flights in July 2008. Note that there were only two flights in July, not four like in the other months (see Table 1). 

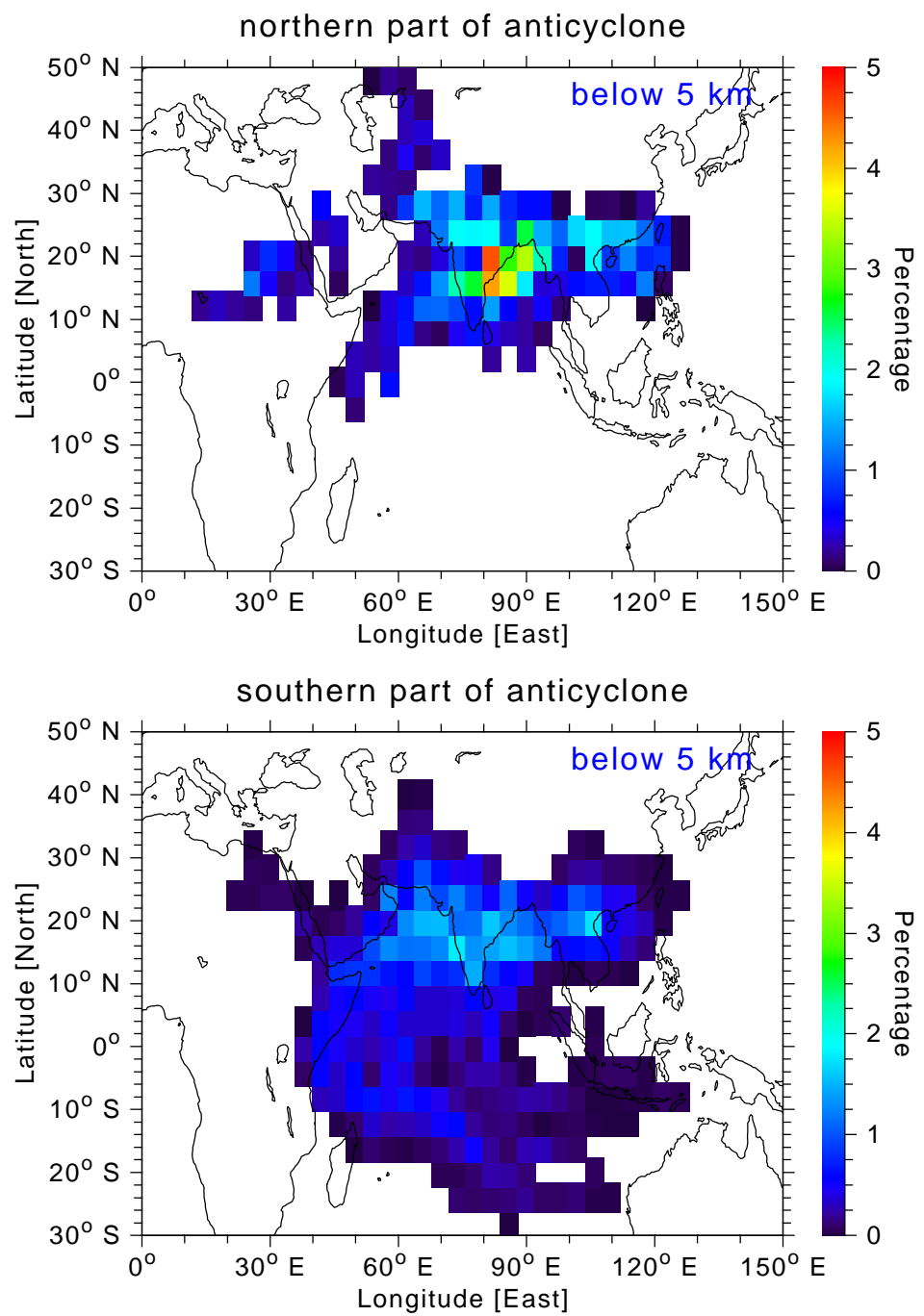

Figure S28. Same as Fig. S26 but for the CARIBIC flights in August 2008. 

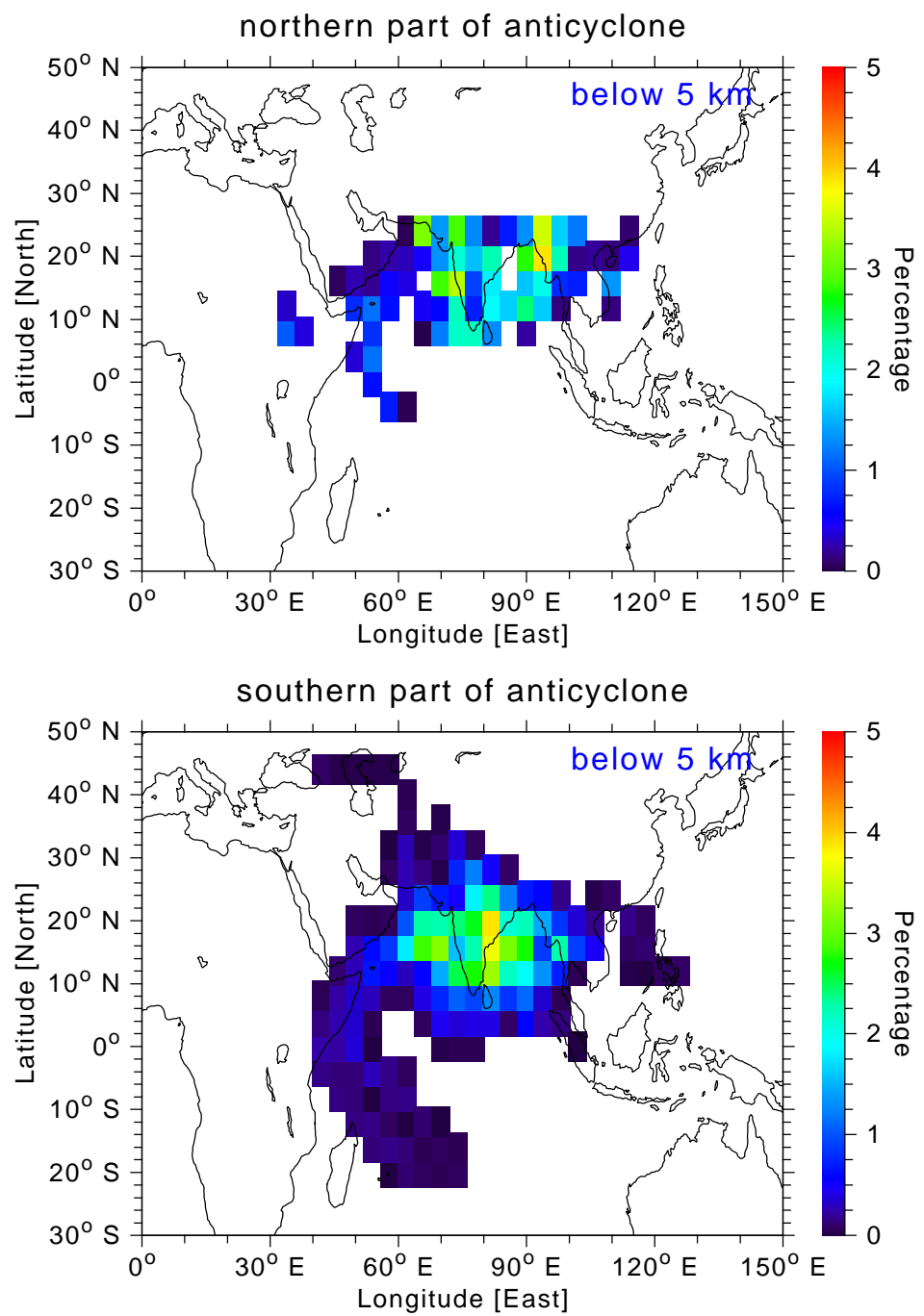

Figure S29. Same as Fig. S26 but for the CARIBIC flights in September 2008. 


\section{S8 Additional monsoon leak rate calculations}

The monsoon is capturing and processing air convected from the surface in its UTAC over the Indian subcontinent. But while most air remains trapped for some time in the UTAC, some fraction can escape either towards the East (to China and the Pacific Ocean) or towards the West (to Africa and the Mediterranean). This "leakage" has been discussed in Sect. 3.3.3. As the UTAC

5 is stronger and presumably more confined in the uppermost troposphere, i.e. above the flight altitude of the CARIBIC aircraft at $\sim 11 \mathrm{~km}-12 \mathrm{~km}$ altitude, it should contain the air masses more intensely at increasing altitudes.

Figs. S30 and S31 show the results calculated from FLEXPART trajectories started $2 \mathrm{~km}$ above the actual flight track for flights in June and in August. At least for altitudes around $13 \mathrm{~km}-14 \mathrm{~km}$ the trapping efficiency is similar to the one at the actual flight altitude.
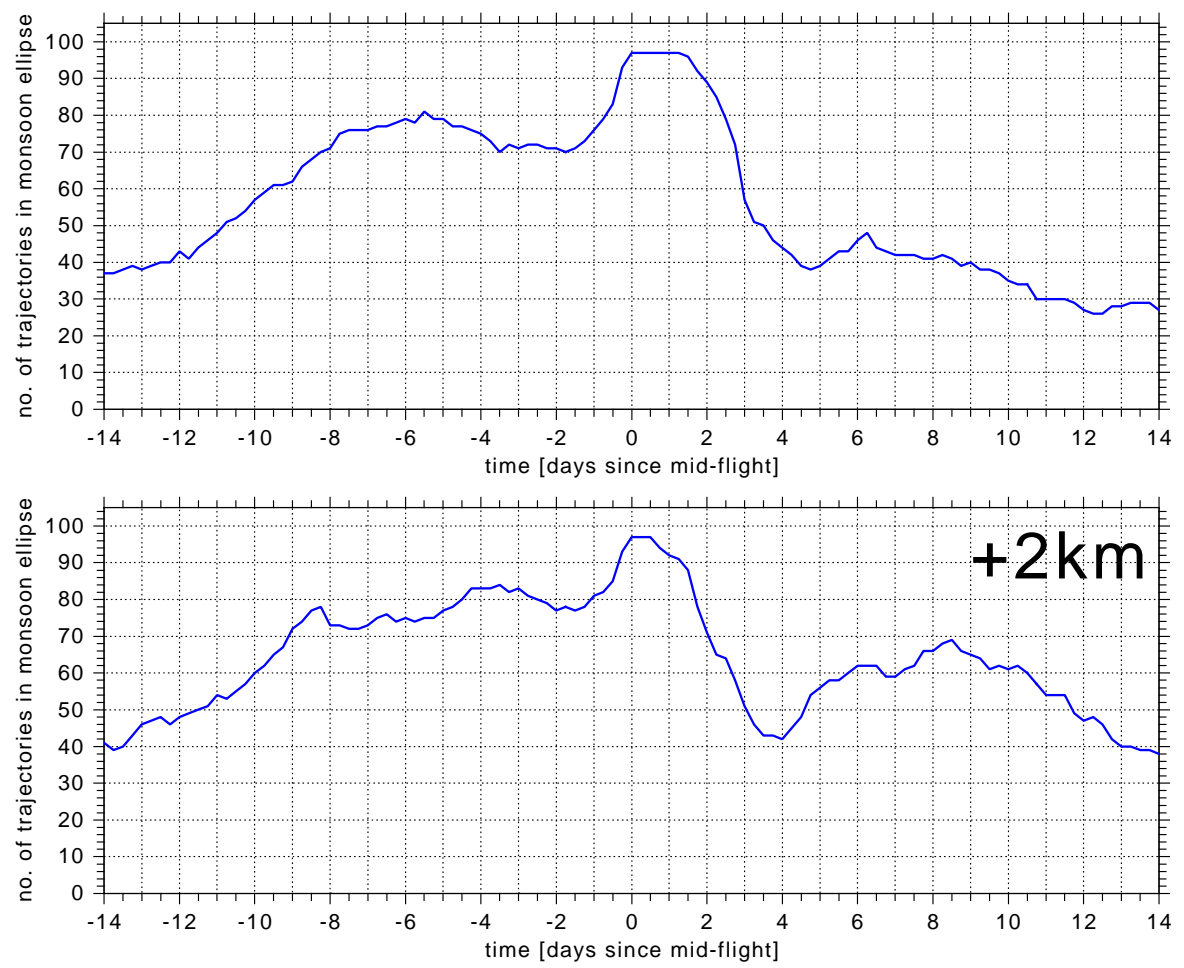

Figure S30. Comparison of the leak rates (see Sect. 3.3.3) for flight 236 to Chennai on 18 June 2008. Shown is the number of trajectories inside the monsoon anticyclone as defined in Table 2 in 6-hourly time steps relative to the time middle of the time the aircraft was in the monsoon anticyclone. The upper diagram shows the calculated leak rate for this flight (see also Fig. 16) while the lower diagram is the leak rate calculated from trajectories started $2 \mathrm{~km}$ higher than the actual CARIBIC aircraft flight track. 

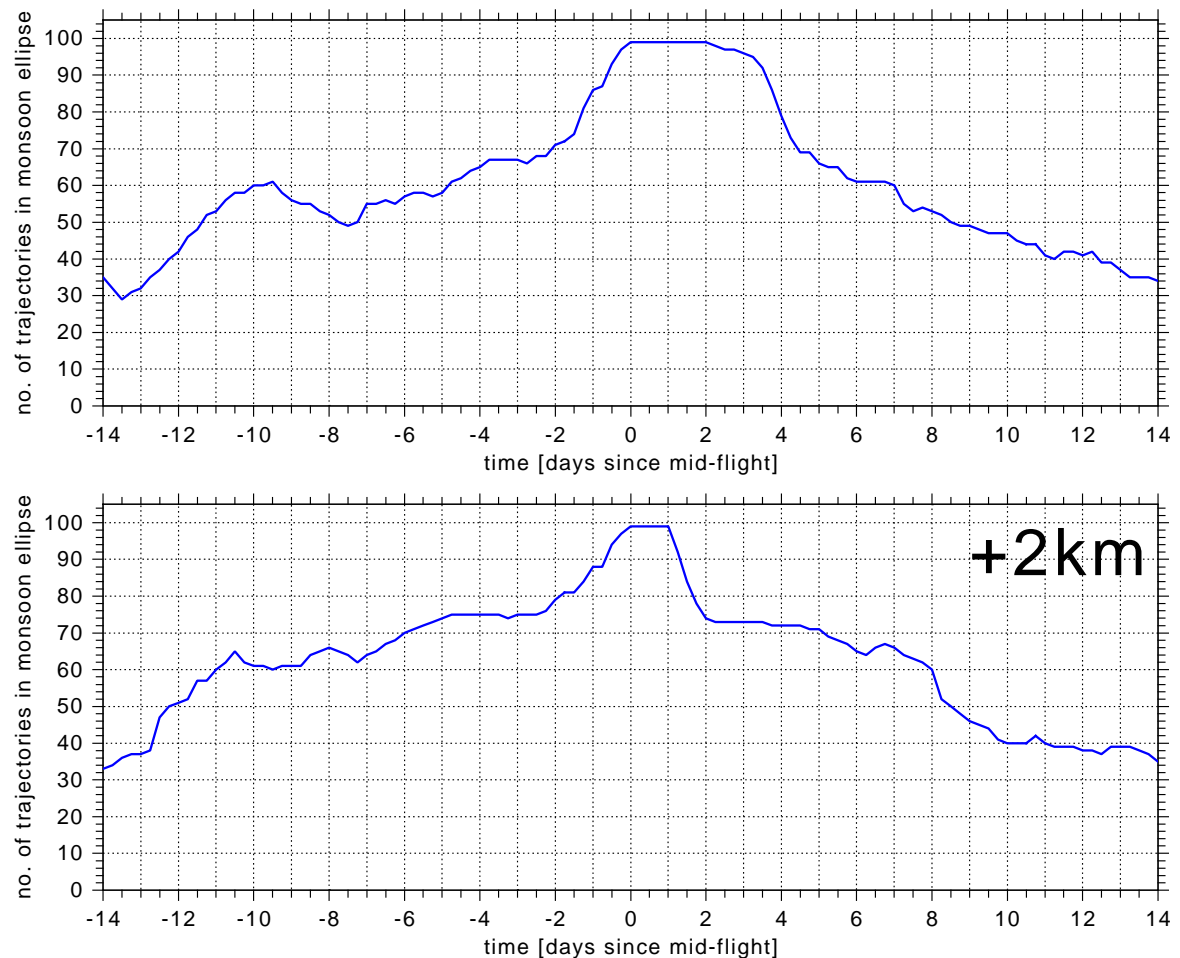

Figure S31. Same as Fig. S30 but for flight 244 to Chennai on 13 August 2008. 


\section{References}

Baker, A. K., Schuck, T. J., Slemr, F., van Velthoven, P., Zahn, A., and Brenninkmeijer, C. A. M.: Characterization of nonmethane hydrocarbons in Asian summer monsoon outflow observed by the CARIBIC aircraft, Atmos. Chem. Phys., 11, 503-518, doi:10.5194/acp-11-503-2011, 2011.

5 Baker, A. K., Schuck, T. J., Brenninkmeijer, C. A. M., Rauthe-Schöch, A., Slemr, F., van Velthoven, P. F. J., and Lelieveld, J.: Estimating the contribution of monsoon-related biogenic production to methane emissions from South Asia using CARIBIC observations, Geophys. Res. Lett., 10, L10813, doi:10.1029/2012GL051756, 2012.

Patra, P. K., Niwa, Y., Schuck, T. J., Brenninkmeijer, C. A. M., Machida, T., Matsueda, H., and Sawa, Y.: Carbon balance of South Asia constrained by passenger aircraft $\mathrm{CO}_{2}$ measurements, Atmos. Chem. Phys., 11, 4163-4175, doi:10.5194/acp-11-4163-2011, 2011.

10 Schuck, T. J., Brenninkmeijer, C. A. M., Baker, A. K., Slemr, F., van Velthoven, P. F. J., and Zahn, A.: Greenhouse gas relationships in the Indian summer monsoon plume measured by the CARIBIC passenger aircraft, Atmos. Chem. Phys., 10, 3965-3984, doi:10.5194/acp-10-3965-2010, 2010.

Stohl, A., Forster, C., Frank, A., Seibert, P., and Wotawa, G.: Technical note: The Lagrangian particle dispersion model FLEXPART version 6.2, Atmos. Chem. Phys., 5, 2461-2474, doi:10.5194/acp-5-2461-2005, 2005.

15 Stohl, A., Sodemann, H., Eckhardt, S., Frank, A., Seibert, P., and G.Wotawa: The Lagrangian particle dispersion model FLEXPART version 8.2, Tech. rep., Norwegian Institute of Air Research (NILU), Kjeller, Norway, available at http://flexpart.eu/, last access: 19 February $2016,2010$.

Umezawa, T., Baker, A. K., Oram, D., Sauvage, C., O’Sullivan, D., Rauthe-Schöch, A., Montzka, S. A., Zahn, A., and Brenninkmeijer, C. A. M.: Methyl chloride in the upper troposphere observed by the CARIBIC passenger aircraft observatory: Large-scale distributions and Asian summer monsoon outflow, J. Geophys. Res., 119, 5542-5558, doi:10.1002/2013JD021396, 2014. 